\title{
Impact of natural versus mechanical ventilation on simulated indoor air quality and energy consumption in offices in fourteen U.S. cities
}

\author{
Tom Ben-David and Michael S. Waring
}

\begin{abstract}
This study simulated the impacts of natural versus mechanical ventilation in offices on indoor concentrations of key pollutants, as well as energy usage. A typical office building was modeled in EnergyPlus in fourteen U.S. cities to assess the energy use and airflows delivered by an ideal variable air volume (VAV) system in a range of climates. Two mechanical ventilation strategies (minimum; minimum + economizer control) were modeled, as well as two analogous natural ventilation strategies, which used a fan-driven recirculation hybrid system to maintain setpoints if necessary. Outputted hourly ventilation, recirculation, and infiltration rates were used in an indoor air model with city-specific outdoor monitoring data to compute indoor concentrations of carbon monoxide, carbon dioxide, formaldehyde, nitrogen dioxide, ozone, and fine particles $\left(\mathrm{PM}_{2.5}\right)$. Natural ventilation decreased energy use, due to a wider temperature setpoint band for natural ventilation scenarios and somewhat lower fan energy use. Indoor concentrations and indoor/outdoor (I/O) ratios of all pollutants were similar for analogous strategies, except $\mathrm{PM}_{2.5}$, which was reduced by filters in the supply air. As such, median $\mathrm{PM}_{2.5} \mathrm{I} / \mathrm{O}$ ratios were a factor of 1.2, 2.2, and 6.3 larger for natural versus mechanical ventilation strategies with MERV 8, 11, and 16 filters, respectively. The filtration impact was so strong that $\mathrm{PM}_{2.5} \mathrm{I} / \mathrm{O}$ ratios differed little between mechanical minimum and economizing strategies, especially as filter efficiency increased. These results can be used to understand tradeoffs of energy and indoor air pollution trends when evaluating natural versus mechanical ventilation.
\end{abstract}

\section{INTRODUCTION}

Buildings demand large amounts of resources. For instance, they consume roughly $40 \%$ of the energy used by the U.S. and $24 \%$ by the world [1], the residential and commercial building sectors are responsible for $40 \%$ of the U.S. carbon dioxide $\left(\mathrm{CO}_{2}\right)$ emissions [2], and building occupants account for $10 \%$ of the U.S. water consumption [3]. Heating, ventilating, and air conditioning (HVAC) systems are used in modern buildings to maintain desired indoor conditions, and these consume two-thirds of the site energy for residential, commercial, and public buildings [4] in the developed world. Ventilation is the intentional exchange of outdoor air with the indoor air, and conditioning ventilation air to the appropriate thermal state can potentially amount to about half of building space-conditioning energy [4]. Ventilation rates may be increased or optimized [5] to enhance occupant productivity [6,7], reduce sick building syndrome [8-10] absenteeism [10, 11], and generally to maintain acceptable indoor air quality [13].

Standards-setting organizations such as ASHRAE or the European Committee for Standardization (CEN) prescribe minimum ventilation rates in buildings. For instance, the minimum ventilation rate in 
U.S. offices at default occupant densities is $8.5 \mathrm{~L} / \mathrm{s} /$ person [13]. Traditionally, fans in air handling units (AHU) in HVAC systems supply ventilation air mechanically, though a newer design paradigm attempts to use natural ventilation to supply air without fans and instead by using wind-driven flows at the building façade [14]. This shift has occurred because natural ventilation can save energy by eliminating the need for fans, by sometimes supplying larger airflow rates than in mechanically ventilated spaces, and by allowing larger allowable ranges of temperature bands in which occupants are comfortable [15]. Of course, natural ventilation alone is not feasible in all climates or at all times of year. However, hybrid approaches are also possible which use a mechanical recirculation system is used to complement natural ventilation to meet loads or which may employ additional operational strategies such as thermal night flushing [16].

Though standards such as ASHRAE 62.1-2013 try to safeguard indoor air quality (IAQ) with ventilation, its actual impact on IAQ is more complex. By its act of bringing in more outdoor air, ventilation has the potential to increase indoor concentrations of outdoor originating pollutants, while decreasing indoor emitted ones [17-19]. In offices, for example, important outdoor sourced pollutants can include particulate matter $(\mathrm{PM})$, ozone $\left(\mathrm{O}_{3}\right)$, and nitrogen dioxide $\left(\mathrm{NO}_{2}\right)$ [20-23], and important indoor emitted pollutants include volatile organic compounds (VOCs) and carbon dioxide $\left(\mathrm{CO}_{2}\right)$ [18,24]. Since Americans spend $\sim 87 \%$ of their time in buildings [25], indoor exposure to these pollutants can be a dominant route [21,26-29]. This exposure is important, as studies suggest that exposures to PM [30-36], ozone $[37,38], \mathrm{NO}_{2}[39,40]$ and certain VOCs $[40,41]$ are associated with increased morbidity and mortality.

There is one major distinction between the impacts of natural versus mechanical ventilation on indoor exposures. Namely, mechanically ventilated buildings have the potential to reduce indoor PM concentrations in a way naturally ventilated spaces cannot, even at high ventilation rates, since those buildings near-universally employ PM filters in the supply airstream [13], through which mechanically ventilated air passes. For instance, Quang et al. [22] demonstrated in three mechanically ventilated offices that filters were efficacious at controlling indoor concentrations of PM of outdoor origin, measuring in-situ efficiencies of 26 to $47 \%$ for fine and ultrafine particles. Modeling also suggests the same conclusion for a variety of building types $[24,42-48]$. Since non-hybrid natural ventilation supplies air only through the 
building envelope, rather than through an AHU, the supply air cannot be filtered before it reaches the building occupants. As a result, one study predicted that locating a naturally ventilated building next to a roadway may lead to indoor PM concentrations near those of outdoors or even up to $20 \%$ higher due to the lack of filtration [49]. As such, the concentration of and exposure to indoor PM of outdoor origin may be greater in naturally versus mechanically ventilated spaces.

To greater understand this impact, as well as the impact of natural versus mechanical ventilation on indoor pollutant concentrations generally, this work explored the differences in indoor concentrations of PM and other important IAQ indicators within offices with mechanical versus natural ventilation, as well as energy use differences. Offices were chosen because they are a typical building type that is operationally amenable to both ventilation types. To assess the impact of these different ventilation paradigms on IAQ, we simulated the transient energy use and ventilation rates using a building energy model of a typical office in 14 U.S. cities, separately considering two natural and two mechanical ventilation strategies. Outputted building airflow rates were used with real outdoor monitoring data in mass balances to predict the indoor concentrations of the indicator pollutants. These results were analyzed to allow more informed decision-making about the impacts of each ventilation type on IAQ in offices.

\section{METHODOLOGY}

\subsection{Simulation overview}

Annual simulations at an hourly timescale were conducted to assess the impacts of four ventilation strategies - two mechanical and two natural — on energy consumption and IAQ in a typical office in 14 representative locations, using their typical meteorological years (TMY) and recent outdoor pollution data. Then, those annual hourly transient results from simulations in the 14 cities were pooled and analyzed as one combined dataset, and outcome trends as functions of influential variables were explored. For the pooled analysis, the pollutant indoor/outdoor (I/O) ratio was our primary parameter of judgment of ventilation strategy impacts, since it is independent of city-to-city pollution variation, though summary 
statistics of absolute concentration distributions in each city are provided as well. The simulation framework is generally introduced in this sub-section, and specific details are given afterward.

A complete simulation herein consisted of a coupled building energy model using U.S. Department of Energy (DOE) EnergyPlus Energy Simulation Software and an indoor concentration model using standard, well-mixed mass balances formulated for offices. EnergyPlus is a validated, physics-based, research-grade energy analysis and thermal load modeling program [50,51] that, for a particular building and climate, calculates the year-long transient heating and cooling necessary to maintain thermal and ventilation setpoints, as well as operational states of the HVAC equipment. First, we used EnergyPlus to model a standard office building with the four ventilation strategies to quantify hourly energy usage and air exchange rates (AER). Then, along with hourly ambient pollution data from 2013 or prior [52], those AERs were used in mass balances with other typical parameters to predict the yearlong, hourly indoor concentrations and I/O ratios of pollutants of interest (e.g., as in Rackes and Waring [18,24]).

For the modeled office in each city, two analogous mechanical and two natural ventilation strategies were simulated, which were chosen based on adherence to current standards [13] or characteristic operational regimes, as well as to facilitate comparisons. The two modeled mechanical ventilation strategies are frequently implemented in real buildings, and they were:

- Mech_min: mechanical ventilation minimum strategy, for which the ventilation rate was constant at the minimum office rate $\left(2.5 \mathrm{~L} / \mathrm{s} /\right.$ person plus $\left.0.3 \mathrm{~L} / \mathrm{s} / \mathrm{m}^{2}\right)$ according to ASHRAE Standard 62.12013 [13].

- Mech_econ: mechanical ventilation economizing strategy, for which more outdoor air is introduced into the indoor space during times when it is thermodynamically favorable (i.e., free cooling), but the ASHRAE Standard 62.1-2013 minimum rate is the operational state otherwise.

The two natural ventilation cases were chosen to mimic the mechanical ventilation cases such that they were tuned to provide nearly the same amount of ventilation air on average, but by using wind-driven flow through the envelope rather than through the AHU. The natural ventilation strategies were:

- Nat_min: natural ventilation minimum strategy, which had rates similar to Mech_min. 
- Nat_econ: natural ventilation economizing strategy, which had rates similar to Mech_econ.

Strictly achieving natural ventilation flows at this level of control is currently operationally infeasible in buildings. However, the strategies modeled herein were designed to facilitate direct comparison of the energy consumption and indoor air concentrations resulting from the ideal implementation of these mechanical and natural ventilation analogues that exist at the ventilation airflow boundaries of low, minimum flow (Mech_min and Nat_min) and high, economizing flow (Mech_econ and Nat_econ). Of course, natural ventilation is not ideal in every climate from a thermal perspective and sometimes may not be capable of meeting the thermal loads. During these times, a hybrid system was automatically employed in which a recirculating air system was used to provide conditioning to help meet the thermal loads. Though the primary purpose of this hybrid system was to condition the recirculated air to meet thermal loads, that recirculation air passes through an AHU and therefore a supply air PM filter.

\subsection{Typical office building locations, properties, and systems}

To select the typical size of the model office building for this study, the Commercial Buildings Energy Consumption Survey (CBECS) was consulted to estimate that the median office building has a floor area of $\sim 450-500 \mathrm{~m}^{2}$ per floor and is two stories in height [53]. However, to be able to conduct a floor-by-floor analysis in future work, a three-story building was modeled instead, and the floor-to-floor height was set at $4.0 \mathrm{~m}$ [54]. To mimic a building shape that would be well designed to maximize natural ventilation, guidance from ASHRAE Research Project 448 [55] indicated that the optimal aspect ratio of the building should be 0.6 , so the footprint dimension of the building was designed as $17.0 \times 28.5 \mathrm{~m}$.

For the simulated locations, the International Energy Conservation Code (IECC) climate regions map was used to select one representative city for different continental U.S. climate regions [56,57]. The regions are divided into climate zones 1 through 7, ranging from very hot to very cold, respectively, with three allowable moisture regimes of humid (A), dry (B), and marine (C). Table 1 summarizes the different cities chosen for the 14 considered climate zones. For each, weather data collected at the nearest airport to each location [58] was used for energy modeling, along with hourly outdoor pollutant concentration data 
from the U.S. Environmental Protection Agency (EPA). For each location, the mean wind speed and resultant direction were culled from the weather data, which are also in Table 1, with the wind direction measured clockwise from true north.

Figure 1(a) illustrates a rendering of the building model geometry created in Google SketchUp. In each location-specific simulation, the building was oriented with its long face normal to the resultant windward direction, as shown in Figure 1(b). The building windows were distributed evenly to attain $\sim 14 \%$ fenestration. The default envelope constructions provided by the U.S. Department of Energy's OpenStudio [59] were used, and default building schedules were maintained as well, which are shown in Figure 2. The insulation thickness was varied to achieve desired wall and roof R-values, listed in Table 1, which were chosen to adhere to climate specific requirements dictated by ASHRAE Standard 90.1-2013 [56]. The lighting density of $9 \mathrm{~W} / \mathrm{m}^{2}$ was also based on ASHRAE Standard 90.1-2013 [56], and an equipment density of $15 \mathrm{~W} / \mathrm{m}^{2}$ was based on Wilkins and Hosni [60]. The occupant density was set at 5 persons per $100 \mathrm{~m}^{2}$, according to default assumptions in ASHRAE Standard 62.1-2013 [13].

The thermal loads of the building were met using an ideal load, variable air volume (VAV) system [50]. Due to the ideality of the system, the loads were met with $100 \%$ efficiency and the percent of outdoor air in the supply airstream was constrained to meet the desired ventilation rate for each ventilation strategy. Although practically unrealistic, this system is designed to capture the difference between mechanically versus naturally ventilated buildings for two similar cases for each ventilation type. EnergyPlus performed the sizing calculations in order to determine the cooling and heating capacities as well as the design airflow rates of the system. Since no specific equipment of particular efficiency was simulated, the output energy consumption was measured by units of annual energy per square meter from generic "District Cooling" and "District Heating" [51]. For the natural ventilation cases, the HVAC system operation was only required when natural ventilation was insufficient to meet the building's temperature setpoints. In these cases, this hybrid system conditioned recirculated air only, as it lacked an outdoor air intake. The system and the ventilation airflows were only operational during occupied hours, defined as from 7:00 AM to 7:00 PM on weekdays (Monday to Friday). 


\subsection{Ventilation and infiltration flow modeling}

The minimum mechanical ventilation rate was set based on ASHRAE Standard 62.1-2013, which requires $2.5 \mathrm{~L} / \mathrm{s}$ per occupant plus an additional $0.3 \mathrm{~L} / \mathrm{s}$ per $\mathrm{m}^{2}$ of occupied floor space [13]. At the default office occupant density of 5 occupants per $100 \mathrm{~m}^{2}$, the standard thus calls for a minimum ventilation rate of $8.5 \mathrm{~L} / \mathrm{s} /$ person or $\sim 206 \mathrm{~L} / \mathrm{s} /$ floor, which equates to a ventilation $\mathrm{AER}=0.383 \mathrm{~h}^{-1}$. Baseline infiltration was estimated at an AER $=0.0418 \mathrm{~h}^{-1}$, which was the value derived using ASHRAE Standard 90.1-2013 and considering an AER $=0.167 \mathrm{~h}^{-1}$ when the building was not pressurized by the mechanical system and then reduced by a factor of 0.25 when the mechanical system is active to account for pressurization impacts of unbalanced outdoor and exhaust airflows [56]. For natural ventilation cases, infiltration was ignored during times when ventilation was active (described below), assuming air favors to travel through natural ventilation paths rather than through envelope leaks, and set to AER $=0.167 \mathrm{~h}^{-1}$ otherwise.

Both natural ventilation and infiltration flows are affected by the dynamic temperature and pressure differences of the outdoor and the indoor environments. Therefore, modeling these flows required a dedicated scheme to simulate their hourly transient behavior that would lead to the desired annual average behavior. We modeled zonal natural ventilation and infiltration using an EnergyPlus formulation that incorporates baseline flow rates with model coefficients, as shown in Equation 1 [50]:

$$
Q=Q_{0} F\left(a+b\left|T_{\mathrm{z}}-T_{\mathrm{OA}}\right|+c v_{\text {wind }}\right)
$$

where $Q\left(\mathrm{~m}^{3} / \mathrm{s}\right)$ is the airflow rate for natural ventilation or infiltration; $Q_{0}\left(\mathrm{~m}^{3} / \mathrm{s}\right)$ is the design airflow rate; $F$ is a fraction set to a predetermined schedule (described below); $T_{\mathrm{z}}\left({ }^{\circ} \mathrm{C}\right)$ and $T_{\mathrm{OA}}\left({ }^{\circ} \mathrm{C}\right)$ are the zonal and outdoor dry bulb air temperatures respectively; $v_{\text {wind }}(\mathrm{m} / \mathrm{s})$ is the wind speed; and $a, b$, and $c$ are constant coefficients, for which we used the Building Load Analysis and System Thermodynamics (BLAST) default coefficients of $0.6060,0.03636$, and 0.1177 , respectively [50]. These coefficients are based on a typical summer condition where the outdoor temperature is equal to the zone temperature and the wind 
speed is $3.35 \mathrm{~m} / \mathrm{s}$. The $c$ coefficients were changed to be location-specific to reflect the actual mean summer wind speed for each city, according to Equation 2:

$$
c_{j}=0.1177 \frac{v_{\text {mean }, j}}{3.35}
$$

where $c_{j}$ is the $c$ coefficient for location $j$; and $v_{\text {mean, } j}(\mathrm{~m} / \mathrm{s})$ is the mean wind speed in location $j$ when the outdoor air temperature is between $18{ }^{\circ} \mathrm{C}$ and $28^{\circ} \mathrm{C}$.

The schedule $(F)$ for the natural ventilation cases was designed to emulate a scenario in which windows would be opened or closed dynamically based on the outdoor air temperature. We therefore designed a window schedule that allowed a fluctuation in natural ventilation rates due to temperature changes to achieve a desired yearlong mean value similar to the mechanical ventilation cases. Since we want to maintain $Q$ as close to $Q_{0}$ as possible so that the natural ventilation strategy mimics the mechanical ventilation strategy, we set them equal to each other. We assumed that at $T_{\mathrm{OA}} \leq 18.3{ }^{\circ} \mathrm{C}$, occupants are expected to start closing windows to some degree. Therefore, for location $j$ during month $m$, the ventilation schedule factor, $F_{j, m}$, was expressed by solving for $F$ in Equation 1, so that:

$$
F_{j, m}=\left\{\begin{array}{cc}
\frac{1}{1+b\left|18.3-T_{\mathrm{OA}, \text { mean }, j, m}\right|} & T_{\mathrm{OA}, \text { mean }, j, m} \leq 18.3 \\
1 & T_{\mathrm{OA}, \text { mean }, j, m}>18.3
\end{array}\right.
$$

where $T_{\mathrm{OA}, \text { mean }, j, m}\left({ }^{\circ} \mathrm{C}\right)$ is mean monthly outdoor air temperature in location $j$ during month $m$, rounded up to the nearest tenth. This scheduling scheme resulted in the Nat_min strategy nearly mimicking ventilation rates for Mech_min on a monthly mean basis. Similarly to the mechanical ventilation, natural ventilation was set to zero during unoccupied hours, as if windows or other means by which natural ventilation is delivered were kept closed during unoccupied times.

For strategy Mech_econ, a temperature-based economizer was applied during cooling cases when the outdoor air temperature was low enough to provide free-cooling effectively, which was capped by the maximum supply airflow that was automatically sized by EnergyPlus, adding the potential for an additional ventilation airflow of $3.15 \mathrm{~h}^{-1}$, so that the year-long mean ventilation AER could attain up to 0.383 
$+3.15=3.53 \mathrm{~h}^{-1}$. The actual ventilation delivered by the economizer strategies was automatically and dynamically employed by EnergyPlus and responded to the real time building loads. To mimic the economizer airflows of Mech_econ for the Nat_econ strategy, additional natural ventilation was added dynamically to the design ventilation rate, $Q_{0}$ such that $Q_{0}$ was equal to the ventilation rate under Mech_econ. The ventilation rate under Nat_econ was still subject to dynamic fluctuation based on the outdoor temperature variation and wind velocity.

\subsection{Temperature setpoints}

We determined indoor temperature setpoints, $T_{\mathrm{SP}}\left({ }^{\circ} \mathrm{C}\right)$, as follows. For the mechanical ventilation cases, the $T_{\mathrm{SP}}$ for heating and cooling were set at $21^{\circ} \mathrm{C}$ and $24{ }^{\circ} \mathrm{C}$, respectively. However, it has been demonstrated that people are comfortable in a wider band of setpoints in naturally versus mechanically ventilated buildings. In fact, de Dear and Brager [15] offered a functional form that relates the acceptable $T_{\mathrm{SP}}$ as a function of the outdoor air temperature $\left(T_{\mathrm{OA}}\right)$ in naturally ventilated buildings:

$$
T_{\mathrm{SP}}=17.8+0.31 T_{\mathrm{OA}}
$$

For natural ventilation cases, we used this formulation for the heating setpoint within the boundaries of 15 ${ }^{\circ} \mathrm{C}$ and $21{ }^{\circ} \mathrm{C}$ and for the cooling setpoint within the boundaries of $24{ }^{\circ} \mathrm{C}$ and $30{ }^{\circ} \mathrm{C}$.

\subsection{IAQ model and pollutant information}

For each pollutant $i$, the rate of change of the indoor concentration $C_{i}\left(\mathrm{ppm}, \mathrm{ppb}\right.$, or $\left.\mu \mathrm{g} / \mathrm{m}^{3}\right)$ is a function of the sources, $S_{i}$, $\left(\mathrm{ppm} / \mathrm{h}, \mathrm{ppb} / \mathrm{h}\right.$, or $\left.\mu \mathrm{g} / \mathrm{m}^{3} / \mathrm{h}\right)$ and the losses, $L_{i}\left(\mathrm{~h}^{-1}\right)$, of the pollutant in that environment, and can be represented as in Equation 5 [17,18,24,43,46,61]:

$$
\frac{\mathrm{d} C_{i}}{\mathrm{~d} t}=S_{i}-L_{i} C_{i}
$$

Inputs to the IAQ model, which included outdoor concentrations for the 14 locations reported by the U.S. EPA [52] and flow rates and schedules outputted by the EnergyPlus simulations, were all sampled hourly 
over a full calendar year. We assumed that within each hour the sources and losses of pollutant $i$ remained constant, which allowed for an analytical solution of the transient process at any hour $k$ with state knowledge of the previous hour $k-1$, as:

$$
C_{i, k}=C_{i, k-1} e^{-L_{i, k}\left(t_{k}-t_{k-1}\right)}+\frac{S_{i, k}}{L_{i, k}}\left(1-e^{-L_{i, k}\left(t_{k}-t_{k-1}\right)}\right)
$$

where any initial value $\left(C_{i, 0}\right)$ was calculated as the steady state solution of the initial hour of measurements. These initial values were necessary to start the annual simulation, as well as to restart the simulation process if there was a lapse in the reported hourly environmental data.

This study considered six different pollutants: (1) carbon dioxide $\left(\mathrm{CO}_{2}\right)$; (2) carbon monoxide (CO); (3) nitrogen dioxide $\left(\mathrm{NO}_{2}\right)$; (4) fine particles $\left(\mathrm{PM}_{2.5}\right)$; (5) ozone $\left(\mathrm{O}_{3}\right)$; and (6) formaldehyde ( $\mathrm{HCHO}$ ). These pollutants were chosen for various reasons. Notably, $\mathrm{PM}_{2.5}, \mathrm{O}_{3}, \mathrm{NO}_{2}$, and $\mathrm{CO}$ are U.S. EPA criteria pollutants. Human exposure to them is associated with health impacts, such as premature morbidity and mortality and occurrences of asthma [30-36,38,62]. Additionally, HCHO is a known human carcinogen [63]. Also, exposure to $\mathrm{CO}_{2}$ and/or VOCs (for which HCHO is a good representative) has been correlated to loss of productivity in simulated task environments [7,64]. All but $\mathrm{CO}_{2}$ may be meaningful contributors to indoor chemistry mechanisms [65]. Finally, from the standpoint of comparing ventilation strategies, $\mathrm{PM}_{2.5}$ is particularly important to include since it is reduced indoors by filtration, which by definition does not occur in natural ventilation strategies except for when hybrid operation is necessary. The pollutant sources and losses are illustrated in Table 2 [24], with explanations of the model parameters and terms in the following subsections. Of the symbols in Table 2 not yet defined, the $\lambda_{\mathrm{v}}, \lambda_{\mathrm{i}}$, and $\lambda_{\mathrm{r}}\left(\mathrm{h}^{-1}\right)$ denote the ventilation, infiltration, and recirculation AERs, respectively, while $V_{\mathrm{z}}\left(\mathrm{m}^{3}\right)$ and $P_{\mathrm{z}}$ (occ) are the zonal volume and number of occupants, respectively.

\subsubsection{Carbon dioxide and carbon monoxide}

In our simulated office, $\mathrm{CO}_{2}$ was generated by the respiration of human occupants and was also introduced by outdoor-to-indoor transport. This pollutant is used as an indicator of IAQ and adequate ven- 
tilation [13]. Newer research also suggests it directly impairs decision-making skills [7,64], though this impact has not been confirmed outside of laboratory experiments. Within the zone, the per occupant respiratory emission rate of $\mathrm{CO}_{2}, E_{\mathrm{CO} 2}$, was $18,530 \mathrm{ppm}-\mathrm{m}^{3} / \mathrm{h} / \mathrm{occ}(\sim 33.3 \mathrm{~g} / \mathrm{h} / \mathrm{occ})$, and the outdoor concentration, $C_{\mathrm{CO} 2 \text {,out }}(\mathrm{ppm})$, was constant at $450 \mathrm{ppm}$ to represent that of a typical urban environment [24]. Regarding $\mathrm{CO}$, its only source in the office environment was outdoor-to-indoor transport, and the outdoor concentration of $\mathrm{CO}, C_{\mathrm{CO} \text {,out }}(\mathrm{ppm})$, was from the hourly EPA data. Both $\mathrm{CO}_{2}$ and $\mathrm{CO}$ are treated as nonreactive and non-sorbing, so their losses were owing to ventilation and infiltration air exchange only.

\subsubsection{Nitrogen dioxide and ozone}

Both $\mathrm{NO}_{2}$ and $\mathrm{O}_{3}$ exist meaningfully in the ambient urban atmosphere, and both can be emitted indoors. For example, $\mathrm{NO}_{2}$ is from combustion processes such as gas-stove use [66], and $\mathrm{O}_{3}$ may be from emissions of copiers or laser printers [67]. However, we assumed that these processes were negligible in our modeled indoor environment and treat outdoor-to-indoor transport as our only sources of these pollutants. Ozone is a dominant oxidizer indoors, though both $\mathrm{NO}_{2}$ and $\mathrm{O}_{3}$ can meaningfully impact indoor chemistry [23,65]. In our model, both $\mathrm{NO}_{2}$ and $\mathrm{O}_{3}$ have losses due to surface reactions, which are termed $\beta_{\mathrm{NO} 2}\left(\mathrm{~h}^{-1}\right)$ and $\beta_{\mathrm{O} 3}\left(\mathrm{~h}^{-1}\right)$, respectively, and their values were set at $1.18 \mathrm{~h}^{-1}$ and $2.80 \mathrm{~h}^{-1}$, respectively $[24,65]$. Ozone was also modeled as being reduced by chemical reactions when infiltration air passes through the building envelope or when recirculation and ventilation air pass through a filter in the mechanical system. These phenomena were quantified, respectively, by a penetration factor, $p_{03}=0.78$ [68], and by a filter removal term $\eta_{\mathrm{r}, \mathrm{O} 3}$ or $\eta_{\mathrm{v}, \mathrm{O} 3}=0.080$ [69]. We set the ventilation efficiency term to zero, i.e., $\eta_{\mathrm{v}, \mathrm{O} 3}=0$, for the natural ventilation cases.

\subsubsection{Formaldehyde}

Formaldehyde (HCHO) and other VOCs are significant indoor pollutants [40]. VOCs are emitted indoors, so their indoor concentrations are often higher than their outdoor concentrations $[24,70]$. Moreover, some VOCs may be emitted indoors as functions of the indoor concentration (which is heavily influ- 
enced by the AER) from both instantaneous [71] and time-averaged perspectives [18]. As such, Rackes and Waring [18] used VOC concentration and AER data, which were collected in 100 buildings as part of the EPA Building Assessment Survey and Evaluation (BASE) study to statistically model whole building, effective emission rates as a function of the AER [18,54], similarly to in [71]. Following that model, the $\mathrm{HCHO}$ emission rate per floor area, $E_{\mathrm{z}, \mathrm{HCHO}}\left(\mathrm{ppb}-\mathrm{m}^{3} / \mathrm{h}-\mathrm{m}^{2}\right)$, was:

$$
E_{\mathrm{z}, \mathrm{HCHO}}=h_{\mathrm{z}} k L \frac{\left(\lambda_{\mathrm{v}}+\lambda_{\mathrm{i}}\right) C_{\mathrm{eq}}-S_{\mathrm{oth}}}{\lambda_{\mathrm{v}}+\lambda_{\mathrm{i}}+k L}
$$

where $h_{\mathrm{Z}}(\mathrm{m})$ is the zone height; $S_{\text {oth }}(\mathrm{ppb} / \mathrm{h})$ is sources of per-person emissions $\left(E_{\mathrm{p}, \mathrm{HCHO}} P_{\mathrm{Z}} / V_{\mathrm{Z}}\right)$ and the outdoor concentration $\left(C_{\mathrm{HCHO}, \text { out }}\left(\lambda_{\mathrm{v}}+\lambda_{\mathrm{i}}\right)\right) ; C_{\mathrm{eq}}(\mathrm{ppb})$ is a conceptual equilibrium concentration at the material-air interface; and $k L\left(\mathrm{~h}^{-1}\right)$ is a coupling time constant between the material surface and room air. The outdoor concentration, $C_{\mathrm{HCHO}, \text { out }}(\mathrm{ppb})$, and per-person emission rate, $E_{\mathrm{p}, \mathrm{HCHO}}\left(\mathrm{ppb}-\mathrm{m}^{3} / \mathrm{h}-\mathrm{occ}\right)$, were constrained at $2.20 \mathrm{ppb}$ and $3.20 \mathrm{ppb}-\mathrm{m}^{3} / \mathrm{h}$-occ, respectively [18]. From Rackes and Waring [18], the HCHO emission parameters were $C_{\mathrm{eq}}=18.2 \mathrm{ppb}$ and $k L=1.6 \mathrm{~h}^{-1}$. Since the emission model was developed with empirical BASE data, which included $~ 100$ buildings under numerous indoor psychrometric conditions, the influence of the variability of the indoor air temperature and $\mathrm{RH}$ on the $\mathrm{HCHO}$ emission rate was included within its parameter fitting but not modeled specifically. To demonstrate the impact of the AERdependent emissions model on $\mathrm{HCHO}$, concentrations were simulated for an additional value of $k L=0.05$ $\mathrm{h}^{-1}$, which makes the emission rate modeled by Equation 8 AER-independent and near constant, as is most often assumed. For comparison, the $C_{\text {eq }}$ for the AER-independent emission model was adjust to equal $122 \mathrm{ppb}$, so that $E_{\mathrm{z}, \mathrm{HCHO}}$ was the same for both emission models in Mech_min.

\subsubsection{Fine particulate matter}

$\mathrm{PM}_{2.5}$ is the only non-gaseous pollutant considered in this study, and it exists at many intensities outdoors and has strong impacts on human health. It exhibits size-resolved behavior, and assumed PM size distributions can be combined with size resolved parameters to estimated integrated parameters for the mass concentration. Relevant size resolved losses indoors include deposition to surfaces and filtration, 
and the PM size distribution shape relates one to the other. Using this relationship, Rackes and Waring [24] fit a quadratic expression to estimate the integrated $\mathrm{PM}_{2.5}$ deposition rate, $\beta_{\mathrm{PM} 2.5}\left(\mathrm{~h}^{-1}\right)$, as a function of the nominal $\mathrm{PM}_{2.5}$ filter efficiency in the recirculation air stream, $\eta_{\mathrm{r}, \mathrm{PM} 2.5}$ :

$$
\beta_{\mathrm{PM}_{2.5}}=0.171 \eta_{\mathrm{r}, \mathrm{PM}_{2.5}}{ }^{2}-0.1378 \eta_{\mathrm{r}, \mathrm{PM}_{2.5}}+0.0918
$$

In our study, three different filter efficiencies $\left(\eta_{\mathrm{r}, \mathrm{PM} 2.5}\right)$ were considered, characterized by the ASHRAE Minimum Efficiency Reporting Value (MERV) of MERV 8, 11, and 16, which were assigned nominal removal efficiencies for $\mathrm{PM}_{2.5}$ of $26.4 \%, 65.6 \%$, and $96.3 \%$, respectively [72]. For the mechanical ventilation cases, the ventilation filter efficiency $\eta_{\mathrm{v}, \mathrm{PM} 2.5}=\eta_{\mathrm{r}, \mathrm{PM} 2.5}$. For the natural ventilation cases, $\eta_{\mathrm{v}, \mathrm{PM} 2.5}=0$. Finally, $\mathrm{PM}_{2.5}$ can be filtered by the cracks in the building envelope when air infiltrates into the building, and we modeled this phenomenon using a penetration factor of $p_{\mathrm{PM} 2.5}=0.975$ [24].

\section{RESULTS AND DISCUSSION}

\subsection{Ventilation summary}

We compared the air exchange rate (AER) results over the ventilation strategies to confirm that the natural ventilation schemes mimicked their mechanical ventilation analogues, using the daily mean ventilation AER in each location for comparison, therefore employing a large dataset for comparing ventilation strategy analogues at a granular level. A cumulative distribution function (CDF) of the mean daily ventilation AERs over all locations is shown in Figure 3a. We also calculated the coefficient of determination $\left(\mathrm{R}^{2}\right)$ between the analogue economizing ventilation strategies over all locations, and they had $\mathrm{R}^{2}=$ 0.98. Based on the CDFs and $\mathrm{R}^{2}$ values, we conclude that the natural ventilation models emulated their mechanical ventilation analogues to a reasonable extent to allow comparisons, while still including the variability of wind and natural ventilation.

We also assessed ventilation AERs by strategy at each location individually. For each ventilation strategy, the median mean daily ventilation AER is presented with the 5th and 95th percentiles in parentheses in Table 3. We also calculated the root mean squared error (RMSE) of the mean daily ventilation 
AERs of Mech_min compared with those of Nat_min, as well as the correlation coefficient (corr) between the mean daily ventilation AER of the two economizing strategies at each location. These errors ranged from $\mathrm{RMSE}=0.049$ to $0.078 \mathrm{~h}^{-1}$ and correlation ranged from corr $=0.81$ to 0.99 for economizing analogues, so the natural ventilation strategies clearly mimicked the mechanical ventilation strategies in all locations to a large degree with the flow models used, albeit with slightly larger spans for natural ventilation cases due to the variability of outdoor temperature and wind and their impacts on airflow.

Since economizer operation is enthalpy-driven, we were interested in observing how ventilation changed with the outdoor air conditions. Consequently, we plotted the mean monthly ventilation AER against the mean monthly outdoor air temperature, as in Figure 3b, pooling the modeling results for all 14 locations. For the two economizing strategies, a similar peak in ventilation AER is clearly observed during times of temperate outdoor air temperatures (e.g., means of $10{ }^{\circ} \mathrm{C}$ to $25^{\circ} \mathrm{C}$ ), though the natural ventilation strategy achieves slightly higher rates than the mechanical analogue. These higher ventilation AERs will affect both fan energy consumption for the mechanical case and pollutant indoor concentrations and I/O ratios when they occur for both types of economizing strategies. Results in Figure $3 \mathrm{~b}$ can be used to estimate ventilation behavior for our modeled building for locations not in our modeling space.

\subsection{Energy consumption}

Simulation results for office energy consumption for each ventilation strategy in each city of the 14 climate zones are presented in Table 4, separated into ideal cooling, heating, and fan energy use. To generalize the energy results beyond the simulated locations and view trends instead according to climate, the monthly cooling, heating, and fan energy consumption data for all 14 locations were pooled and plotted in Figure 4a against the mean monthly outdoor air temperature. In addition to the nominal ideal energy consumption values, Figure $4 \mathrm{~d}-\mathrm{f}$ plots the energy savings relative to the base case Mech_min for each of the three other ventilation strategies, since this relative comparison allows one to better observe energy saving trends by strategy for different mean outdoor conditions. 
Considering Mech_min as the baseline case, cooling energy was universally reduced under the three other strategies, for reasons as follows. Firstly, the mechanical economizing case, Mech_econ, and its natural ventilation analogue, Nat_econ, often used free rather than coil-driven cooling during swing and winter seasons to meet cooling loads. Moreover, the wider setpoint band of natural ventilation strategies of Nat_min and Nat_econ yielded a load reduction. Since Nat_econ takes advantage of both of these opportunities, it universally exhibited the largest savings in cooling energy for all strategies.

Over all locations, heating energy consumption in Mech_econ was identical to heating energy consumption in Mech_min. This equality is expected, since economizing only impacts the amount of cooling and fan energy used. Conversely, the heating energy for the two natural ventilation cases was typically reduced compared with their mechanical analogues, due to the wider setpoint band. The Nat_econ heating energy use was always larger than Nat_min cases, owing to the higher ventilation AERs. However, both natural ventilation strategies occasionally had larger heating energy use as compared with their mechanical analogues for some outlying cases, as can be seen in Figure 4 during warmer months that still required some heating. These heating trends are a consequence of the natural ventilation airflow model, which mimics mechanical analogue flow rates but still has variation due to extreme outdoor conditions. Thus, the actual transient temperature and wind velocities in each climate in the TMY datasets dictate the natural ventilation airflows (see Equation 1) that sometimes result in the introduction of larger amounts of colder air indoors during the heating season.

Additionally, fan energy consumption is presented in Table 4 and Figure 4 . When the economizer is used in Mech_econ, it supplies additional ventilation air mechanically, causing the fan to work more. This operation produces increases in fan energy consumption during temperate months, as seen in Figure 5. On the other hand, for Nat_econ, the additional ventilation air is not moved by fan power and the freecooling usage causes a thermal load reduction and requires no hybrid fan energy during these temperate months. The thermal load reduction due to the wider setpoint band also allows for further reduction in fan energy consumption under both natural ventilation strategies. Generally, one can see increased savings in fan energy in the natural ventilation cases as the outdoor air temperature increases. That said, fan energy 
changes among strategies are one order of magnitude smaller than savings generated by heating or cooling energy reductions among ventilation strategies.

Table 4 includes the percent of time when economizing was utilized for the two relevant strategies, so that one may discern the differences for the natural over the mechanical ventilation operation. Moreover, we included in Table 4 the percent of time during which the hybrid operation was employed by the natural ventilation cases (i.e., when natural ventilation alone could not maintaining indoor air setpoints and a recirculating mechanical system was used to complement it), which is useful to interpret the impact of the hybrid recirculation-influenced filtration on $\mathrm{PM}_{2.5}$ for Nat_min and Nat_econ cases. Relatedly, Figure 5a plots a CDF of the mean daily return air AER over all locations under each strategy, and Figure $5 \mathrm{~b}$ plots the mean monthly return AER as a function of the mean monthly outdoor air temperature. Since the return air AER demonstrates the total amount of airflow that passes through the filter-for mechanical strategies it approximates ventilation + recirculation (i.e., supply) AERs and for natural ventilation strategies it equals the recirculation AER owing to the hybrid strategy — it is therefore a direct indicator of the efficacy of the filter on reducing indoor $\mathrm{PM}_{2.5}$ concentrations for each strategy.

\subsection{Indoor pollutant absolute concentrations}

We simulated hourly indoor concentrations of the six pollutants over an entire year, but only those during occupied hours were considered in this analysis, since they are the only ones that would influence occupant exposure. Individual pollutants exhibited distinctive trends as functions of ventilation strategy or location, depending on their particular source and loss profiles. Both $\mathrm{CO}_{2}$ and $\mathrm{HCHO}$ had constant simulated outdoor concentrations across cities (450 ppm and $2.2 \mathrm{ppb}$, respectively) and rather stable indoor emission rates, so factors affecting their indoor concentrations were the ventilation AER and the number of occupants. Owing to these factors, variations in $\mathrm{CO}_{2}$ and $\mathrm{HCHO}$ concentrations were significant when compared across certain ventilation strategies, but city-to-city concentration variations were largely insignificant. That is, Mech_min and Nat_min ventilation cases resulted in similar sets of indoor concentrations for both pollutants, and Mech_econ and Nat_econ cases resulted in other similar sets of 
concentrations. For $\mathrm{CO}_{2}$ and $\mathrm{HCHO}$ indoor concentration distributions, medians and 5th and 95th percentiles are presented in Table 5. Additionally, Figure 6 includes CDFs of HCHO indoor concentrations for representative location 4A: Philadelphia, PA, with separate plots for the two $k L$ values.

These $\mathrm{CO}_{2}$ distributions reflect the magnitude one would expect for an office at default occupant densities that was ventilated at the ASHRAE minimum rate or greater $[13,54]$. For the two minimum rate cases, $\mathrm{CO}_{2}$ distributions had a median of $\sim 810 \mathrm{ppm}$, which was $\sim 175 \mathrm{ppm}$ higher than their economizing counterparts. Though median $\mathrm{CO}_{2}$ concentrations were different for the minimum versus economizing ventilation cases, all four ventilation strategies resulted in similar $\mathrm{CO}_{2}$ ranges. On average, they all existed within a $90 \%$ confidence interval (CI) of $\sim 465$ to 965 ppm, although the two natural ventilation $\mathrm{CO}_{2}$ distributions exhibited slightly longer upper tails due to low ventilation AERs driven by variability in the TMY ambient temperatures and wind velocities over the modeled locations.

The best estimate HCHO concentration distributions are those predicted with the AER-dependent model at $k L=1.6 \mathrm{~h}^{-1}$ [18], and simulated values are similar to those measured in offices [54]. The HCHO distributions predicted using the AER-independent model $\left(k L=0.05 \mathrm{~h}^{-1}\right)$ demonstrate the concentration outcomes (and tendency to error, we believe) when assuming HCHO emissions are AER-independent and constant. Indeed, $\mathrm{HCHO}$ concentration distributions were more different across the $k L$ values than across ventilation strategies, showing the importance of appropriately modeling the variability of the emission rate with AER when estimating indoor VOCs. The AER-independent predicted concentrations were much more variant than AER-dependent ones because the higher $k L=1.6 \mathrm{~h}^{-1}$ of the AER-dependent model drives the indoor $\mathrm{HCHO}$ concentration closer to $C_{\mathrm{eq}}$ and lessens effects of ventilation. (See Rackes and Waring [18] for more discussion on this phenomenon.) Also, the HCHO distributions had similar median and somewhat similar upper tails over the four ventilation cases for each $k L$, though the economizing analogues differed from the minimum ventilation cases by having much longer lower tails, because these lowest concentrations are realized at the highest AERs resulting from economizer operation.

For CO, since its only source is outdoor air and it is treated as non-reactive and non-sorptive in the simulations, indoor concentrations were nearly identical to outdoor ones. Any small differences were 
only due to lag and storage effects of the outdoor air exchanging with that within the indoor space. Therefore, $\mathrm{CO}$ concentrations were effectively independent of the ventilation strategy used. However, $\mathrm{CO}$ distributions did vary by location due to different ambient concentrations. The location-specific indoor CO concentration distributions are summarized in Table 6.

Since $\mathrm{NO}_{2}$ and $\mathrm{O}_{3}$ were of outdoor origin only and are reactive, both had much smaller indoor concentrations than their respective outdoor counterparts. The strength of that concentration reduction varied over the four ventilation strategies. Similarly to $\mathrm{CO}_{2}$ and $\mathrm{HCHO}$ results, the $\mathrm{NO}_{2}$ and $\mathrm{O}_{3}$ were strongly affected by the economizing process of Mech_econ and Nat_econ. However, being of outdoor origin only, indoor $\mathrm{NO}_{2}$ and $\mathrm{O}_{3}$ concentrations also varied strongly by location. Distribution values for the outdoor concentrations, as well as indoor concentrations of $\mathrm{NO}_{2}$ and $\mathrm{O}_{3}$ by ventilation strategy, are listed by location in Table 7. At the medians, the economizing strategies resulted in concentrations that were a factor of $\sim 1.5$ larger than their minimum ventilation counterparts for both $\mathrm{NO}_{2}$ and $\mathrm{O}_{3}$. Finally, because $\mathrm{O}_{3}$ was removed by the HVAC filter at a low efficiency, this removal mechanism did not manifest itself meaningfully in differences between mechanical and natural ventilation strategy analogues.

For $\mathrm{PM}_{2.5}$, the location-specific ambient and indoor concentrations distributions are also listed in Table 7 and are typical of those measured in U.S. offices [54]. Additionally, Figure 7 shows CDFs of the $\mathrm{PM}_{2.5}$ concentration in representative climate zone 4A: Philadelphia, PA for the three different MERV filters. Notably, $\mathrm{PM}_{2.5}$ was the only pollutant in the simulations strongly influenced by whether ventilation was natural versus mechanical in nature, because aerosol filtration is made possible by mechanical airflow. In fact, the filtration impact was so strong that results of Mech_min compared with Mech_econ were largely indistinguishable, most especially as the filtration efficiency increased from MERV 8 to 11 to 16.

Moreover, though filtration can have an impact on the $\mathrm{PM}_{2.5}$ concentration when the natural ventilation is employed owing to the hybrid operation of using recirculated air to meet thermal loads when necessary, this effect is still weak enough that Mech_econ always had lower indoor concentrations than Nat_min, even with the lowest efficiency MERV 8 filter. Expectedly, the Nat_econ case, which had the highest ventilation AERs and little filtration, exhibited the largest $\mathrm{PM}_{2.5}$ concentrations. Since $\mathrm{PM}_{2.5}$ was 
the only pollutant that had meaningful differences in natural versus mechanical cases, we use it as the primary metric of comparing IAQ differences under the mechanical versus natural ventilation.

\subsection{Pollutant indoor/outdoor (I/O) ratios}

Beyond absolute indoor concentrations, the impacts of a ventilation strategy on indoor pollution are more obvious according to its influence on the indoor/outdoor $(\mathrm{I} / \mathrm{O})$ ratio, since that metric is more independent of the variability in outdoor pollutant concentrations. Therefore, the mean monthly I/O ratios for all pollutants in this study, as well as the $\mathrm{PM}_{2.5} \mathrm{I} / \mathrm{O}$ ratios for each MERV filter, were plotted against mean monthly ventilation AER in Figure 8. Correspondingly, Table 8 lists the median (5th and 95th) percentiles of the I/O ratios for each pollutant under Mech_min and Nat_min strategies with a parameter, $k_{i}$, equal to the square of the ratio of 95 th and 5th percentiles, as well as the linear fits, $\mathrm{R}^{2}$, and root mean squared error (RMSE) for the I/O ratio as a function of the range of mean monthly ventilation AER when economizing. The I/O ratios have good fit parameters, reinforcing the strong linear relationships demonstrated in Figure 8 . We note that certain fits have low $\mathrm{R}^{2}$ values, mostly due to their I/O ratios having little change with the ventilation AER (i.e., a flat slope). However, all fits have low RMSE. For PM 2.5 for example, the linear fits well predict the I/O ratio as a function of ventilation AER with an accuracy of $<$ $11 \%$ of the outdoor concentration for Mech_econ and $<17 \%$ of the outdoor concentration for Nat_econ strategies. These fits are useful for estimating I/O ratios at different AERs under various ventilation regimes for use in concentration and exposure modeling and risk assessment.

Between the minimum Mech_min and Nat_min strategies, the I/O ratios changed little for gaseous pollutants of $\mathrm{CO}_{2}, \mathrm{HCHO}, \mathrm{CO}, \mathrm{NO}_{2}$, and $\mathrm{O}_{3}$, due to their nearly equivalent ventilation AERs in the modeling and the fact that these analogues had no differences in indoor losses. For these gases, the I/O ratios also had small variability within each of the minimum strategies. As such, the $k_{i}$ parameters of the gaseous I/O ratios are all within $30 \%$ of unity for the Mech_min and slightly higher for Nat_min, indicating a narrow range of change across cities or during different times of year. For $\mathrm{PM}_{2.5}$, while its $k_{i}$ parameters 
for the I/O ratios under Mech_min and Nat_min are relatively larger, the nominal spreads seen in the confidence intervals are low and the high $k_{i}$ appear due to the small magnitudes of these $\mathrm{PM}_{2.5} \mathrm{I} / \mathrm{O}$ ratios.

Also, for $\mathrm{PM}_{2.5}$, there were notable differences between the minimum strategies, and the $\mathrm{PM}_{2.5}$ I/O ratios for Nat_min were higher than Mech_min since the natural ventilation strategy used active filtration only when air was recirculated by the hybrid system during times of extreme outdoor temperatures. Table 4 and Figure 4 summarize the hybrid operational times, and to further aid in interpretation, Table 8 separately lists I/O ratios for $\mathrm{PM}_{2.5}$ when the outdoor air temperature $\left(T_{\mathrm{OA}}\right)$ is above or below the simulated building's balance temperature $\left(T_{\text {bal }}=17.5^{\circ} \mathrm{C}\right)$. Because low ambient temperatures can sometimes offset cooling needs but outdoor temperatures higher than the balance temperature always require cooling (and associated filtration), $\mathrm{PM}_{2.5} \mathrm{I} / \mathrm{O}$ ratios are lower when $T_{\mathrm{OA}}>T_{\text {bal. }}$ Furthermore, the filter MERV had a large impact on $\mathrm{I} / \mathrm{O}$ ratios for $\mathrm{PM}_{2.5}$, so the differences in $\mathrm{PM}_{2.5} \mathrm{I} / \mathrm{O}$ ratios due to the impact of filtration between the Mech_min and Nat_min strategies increased as the filter MERV improved.

For economizing cases of Mech_econ and Nat_econ, the linear fits of I/O ratios as functions of ventilation AERs are instructive. By substituting the baseline minimum AER $=0.383 \mathrm{~h}^{-1}$ into $\lambda_{\mathrm{v}}$ for the fits in Table 8, one recovers the central tendency of the $\mathrm{I} / \mathrm{O}$ ratio at the minimum condition for any pollutant. These values are slightly lower than minimum strategy medians for the I/O ratio distributions of pollutants of outdoor origin, and vice versa for pollutants of indoor origin. All pollutants were linear functions of the ventilation AER except for $\mathrm{CO}$, which changed little with ventilation since it was non reactive and without indoor sources. The fits for $\mathrm{CO}_{2}, \mathrm{HCHO}, \mathrm{NO}_{2}$, and $\mathrm{O}_{3}$ were basically independent of whether the economizing was driven by mechanical or natural ventilation, owing to there being no or little (for $\mathrm{O}_{3}$ only) removal by the HVAC filter for these pollutants. Their linear fit slope intensities depend on pollutant source strengths, and the sign of slope on whether source profiles were outdoor or indoor dominated. Therefore, slopes were negative for indoor generated $\mathrm{CO}_{2}$ and $\mathrm{HCHO}$, and there were larger $\mathrm{I} / \mathrm{O}$ ratios and a more negative slope for HCHO predicted with the AER-independent versus AER-dependent models. Conversely, slopes were positive for $\mathrm{O}_{3}$ and $\mathrm{NO}_{2}$, and they were slightly higher for $\mathrm{NO}_{2}$ since it is less reactive indoors than $\mathrm{O}_{3}$ under the surface reactivity assumptions used in this model. 
Opposite than the gases, $\mathrm{PM}_{2.5}$ demonstrated clear differences among the Mech_econ and Nat_econ strategies regarding its linear fits of I/O ratios with ventilation AER. Moreover, for the same reason discussed earlier, the $\mathrm{PM}_{2.5} \mathrm{I} / \mathrm{O}$ ratios and linear fit parameters exhibited two distinct trends within each strategy, one when outdoor temperatures $\left(T_{\mathrm{OA}}\right)$ were lower and one when $T_{\mathrm{OA}}$ were higher than the balance temperature $\left(T_{\mathrm{bal}}=17.5^{\circ} \mathrm{C}\right)$. For both economizing strategies, during the warmer months $\left(T_{\mathrm{OA}}>\right.$ $\left.T_{\text {bal }}\right)$, the slopes are steeper due to the use of recirculation to meet loads, while during the cooler months $\left(T_{\mathrm{OA}}<T_{\mathrm{bal}}\right)$, the slopes are flatter and change less with ventilation. Also, for Mech_econ, the slopes decreased as the filter MERV increased, no matter the $T_{\mathrm{OA}}$. For Nat_econ, however, the trends are reversed and the slopes increase with MERV filter efficiency, meaning higher efficiency filtration leads to the $\mathrm{PM}_{2.5}$ I/O ratio increasing more per associated ventilation AER unit change. For this case, a higher ventilation rate indicates that a smaller thermal load is required to condition the building, as inferred by the fact that the system is economizing, and therefore we observe a decrease in hybrid operation and return air and hence less efficacious filtration (see Figure 4b).

Since the ventilation rate is dynamic and enthalpy-driven in the economizing strategies, we also plotted the mean monthly I/O ratios of each pollutant against the mean monthly outdoor air temperature in Figure 9. This plot allows one to estimate the impacts of ventilation strategies across a range of climates and seasons. Figure 9 demonstrates that for $\mathrm{CO}_{2}$ and $\mathrm{HCHO}$, both of which have strong indoor sources, there is a significant decrease in $\mathrm{I} / \mathrm{O}$ ratios when economizing is employed during temperate months by the Mech_econ and Nat_econ strategies. For $\mathrm{NO}_{2}$ and $\mathrm{O}_{3}$, which have indoor concentrations entirely driven by outdoor sources in this model, a reverse trend occurs. For $\mathrm{CO}$, which would have a steady state concentration equal to its outdoor concentration, we observe an I/O ratio of near unity throughout all possible U.S. climates, seasons, and ventilation strategies. Again, due to similar losses, the trends of I/O ratios for these gases are nearly identical when comparing the mechanical ventilation strategies to their corresponding natural ventilation analogues.

In contrast with the gases, the $\mathrm{PM}_{2.5} \mathrm{I} / \mathrm{O}$ ratios strongly varied between ventilation analogues at different mean monthly temperatures. I/O ratios for mechanical strategies were always lower than natural 
ventilation strategies, particularly for economizing times. Indeed, for Mech_Econ, the $\mathrm{PM}_{2.5} \mathrm{I} / \mathrm{O}$ ratios were little affected by higher economizing ventilation AERs - especially as the MERV filter efficiency increased - even though the ventilation rate increased sometimes by an order of magnitude over minimum rates to take advantage of free cooling. In fact, the impact of higher efficiency filtration was so strong that $\mathrm{PM}_{2.5} \mathrm{I} / \mathrm{O}$ ratios were almost identical under Mech_min and Mech_econ strategies for each MERV filter, and were independent of whether the system was economizing. Conversely, filtration had a minimal effect on $\mathrm{PM}_{2.5} \mathrm{I} / \mathrm{O}$ ratios for Nat_min and Nat_econ strategies, and use of these strategies would lead to higher $\mathrm{PM}_{2.5}$ exposures, especially during temperate months. One can observe a small decrease of $\mathrm{PM}_{2.5}$ I/O ratios in warm climates for naturally ventilated offices due to the hybrid operation that allows the use of a recirculation air filter (see Table 4 and Figure 4 for hybrid operational information).

\subsection{Assumptions and limitations}

This simulation study compared the impacts of natural versus mechanical ventilation strategies on energy consumption and IAQ parameters in an office. It compared absolute differences and quantified trends of how I/O ratios change as a function of ventilation AER, for analogous natural and mechanical ventilation strategies. When interpreting the results, there are a number of assumptions and limitations that must be kept in mind. The first and most important is that this study was meant as an ideal investigation of the limits of pollutant concentrations and I/O ratios at the natural and mechanical ventilation boundaries of strict minimums and economizing at full thermodynamic potential. Since it was ideal, we neglected many HVAC system implementation issues, such as difficulties in supplying natural ventilation effectively to all building zones; the inability of multi-zone VAV systems to supply ventilation well to all zones in general; and the inability of building openings to be controlled in coordination with transient wind directions such that flow rates mimic mechanically driven flows.

Regarding simulation-specific issues, the HVAC system was ideal in that particular equipment components with their various efficiencies were not specified. Therefore, the energy consumption values should not be taken as representative at their nominal values, but reasonable average efficiencies for dif- 
ferent equipment could be applied if desired. However, changes in energy use between strategies can be readily compared to impacts of changes in IAQ behavior for ventilation strategies during different ambient conditions (both are presented as a function of the mean monthly outdoor air temperature). Moreover, the IAQ model comprised many assumptions, such as that the indoor air was well mixed, which is likely a less good assumption for natural ventilation; that no indoor particle formation occurred due to indoor chemistry [73-77] and that particles could be treated as nonvolatile [78]; that outdoor and emission conditions were constant over each hour; and that the losses were constant over an annual or daily schedule.

Finally, a streamlined set of indoor air pollutants was analyzed, and one discrete office building with one HVAC system-type was simulated.

\subsection{Summary and conclusions}

Though this simulation study was ideal and made assumptions, the trends understood from both the energy and IAQ analyses are instructive of potential manifestations of impacts in real buildings. The energy consumption data can be coupled with the IAQ predictions, and for a given mean monthly outdoor air temperature and ventilation strategy, the energy consumption from heating, cooling and fan energy as well as the I/O ratios of the modeled pollutants can be contextualized. Additionally, the I/O ratios of the modeled pollutants can be predicted as a function of average ventilation AER, using fits in Table 8 . For each AER, the energy consumption (or savings) due to ventilation can be computed, and since the AERs dictate the I/O ratios of indoor pollutants in a predictable manner, tradeoffs between the two can be estimated in order to explore ventilation strategy impacts on office IAQ and energy consumption.

This study showed that using natural instead of mechanical ventilation can result in changes in both energy use and indoor air concentrations. Specific conclusions this study reached were:

- Cooling energy was reduced under all ventilation strategies compared to the mechanical minimum strategy, with the natural ventilation economizing strategy showing the largest reduction since it uses economizing and allows a wider temperature setpoint band. 
- Heating energy was often reduced by natural ventilation strategies, due to the wider setpoint band allowed with natural ventilation strategies.

- Fan energy changes were an order of magnitude smaller than heating or cooling energy saving possibilities among strategies, and it should not be considered as a driver of decision-making.

- Regarding gases, $\mathrm{CO}_{2}$ and $\mathrm{HCHO}$ were most affected by whether ventilation was at a constant minimum or allowed to economize, and they were little affected by location. However, $\mathrm{O}_{3}$ and $\mathrm{NO}_{3}$ were also affected by location since their outdoor variability is greater. These four pollutants were generally independent of whether ventilation was natural or mechanical. Finally, CO was little affected by any of the variables altered in this work except the outdoor concentration.

- Regarding particles, $\mathrm{PM}_{2.5}$ was affected by all changed variables, including whether ventilation was at a constant minimum or economizing, whether it was natural or mechanical, and by location. Moreover, higher filter efficiency filtration greatly reduced indoor $\mathrm{PM}_{2.5}$ concentrations.

- For economizing operation, since higher ventilation rates elevate outdoor originating pollutants and reduce indoor originating pollutants, the outdoor originating pollutants have higher I/O ratios during temperate months as compared to more extreme hot or cold months, and vice versa for indoor-originating pollutants. However, for $\mathrm{PM}_{2.5}$, the use of high efficiency filtration leads to little difference between mechanical minimum and economizing ventilation strategies.

- In our modeled climates, there was often a need to use a hybrid recirculating system in conjunction with natural ventilation strategies to maintain comfort conditions, but the associated filtration impact was rarely strong enough to match that of mechanical ventilation strategy filtration.

Therefore, natural ventilation may be somewhat desirable to reduce heating and cooling loads. As long as natural ventilation air delivery could be controlled well, the IAQ difference may be minimal for all pollutants except $\mathrm{PM}_{2.5}$, which cannot be filtered effectively when outdoor air is delivered through building openings rather than by an AHU. Conversely, filtration was highly mitigating for both mechanical ventilation strategies. Thus, for $\mathrm{PM}_{2.5}$, understanding the climate, ventilation strategy, and filtration efficiency 
is necessary to predict $\mathrm{I} / \mathrm{O}$ ratio trends. Though $\mathrm{PM}_{2.5}$ was the only pollutant affected by the use of natural versus mechanical ventilation, this $\mathrm{PM}_{2.5}$ concentration change is meaningful owing to the extensive chronic health impacts that may result from exposure to $\mathrm{PM}_{2.5}$ concentrations $[34,40,79,80]$. Therefore, we suggest that the use of natural ventilation needs to be further assessed within a health and monetary framework as a tradeoff between energy savings and elevation of indoor PM to determine its appropriateness and favorability over mechanical ventilation.

\section{ACKNOWLEDGEMENTS}

This work was partially supported by the U.S. National Science Foundation under Grant No. 1511151.

We thank Taylor Castonguay for help with data collection and organization.

\section{REFERENCES}

[1] L. Pérez-Lombard, J. Ortiz, C. Pout, A review on buildings energy consumption information, Energy Build. 40 (2008) 394-398. doi:10.1016/j.enbuild.2007.03.007.

[2] U.S. EIA, Emissions of Greenhouse Gases in the United States 2009, U.S. Energy Information Administration, 2011.

[3] U.S. DOE, Buildings Energy Databook. Energy Efficiency \& Renewable Energy Department., (2012).

[4] M. Orme, Estimates of the energy impact of ventilation and associated financial expenditures, Energy Build. 33 (2001) 199-205. doi:10.1016/S0378-7788(00)00082-7.

[5] A. Rackes, M.S. Waring, Using multiobjective optimizations to discover dynamic building ventilation strategies that can improve indoor air quality and reduce energy use, Energy Build. 75 (2014) 272-280. doi:10.1016/j.enbuild.2014.02.024.

[6] O. Seppänen, W.J. Fisk, Q.H. Lei, Ventilation and performance in office work, Indoor Air. 16 (2006) 28-36. doi:10.1111/j.1600-0668.2005.00394.x.

[7] U. Satish, M.J. Mendell, K. Shekhar, T. Hotchi, D. Sullivan, S. Streufert, et al., Is CO2 an indoor pollutant? Direct effects of low-to-moderate CO2 concentrations on human decision-making performance, Environ. Health Perspect. 120 (2012) 1671-1677. doi:10.1289/ehp.1104789.

[8] M.G. Apte, W.J. Fisk, J.M. Daisey, Associations Between Indoor CO2 Concentrations and Sick Building Syndrome Symptoms in U.S. Office Buildings: An Analysis of the 1994-1996 BASE Study Data, Indoor Air. 10 (2000) 246-257. doi:10.1034/j.1600-0668.2000.010004246.x.

[9] W.J. Fisk, A.G. Mirer, M.J. Mendell, Quantification of the association of ventilation rates with sick building syndrome symptoms, Lawrence Berkeley Natl. Lab. (2009). http://escholarship.org/uc/item/2d10c901 (accessed February 4, 2016).

[10] J. Sundell, H. Levin, W.W. Nazaroff, W.S. Cain, W.J. Fisk, D.T. Grimsrud, et al., Ventilation rates and health: multidisciplinary review of the scientific literature, Indoor Air. 21 (2011) 191-204. doi:10.1111/j.1600-0668.2010.00703.x.

[11] D.K. Milton, P.M. Glencross, M.D. Walters, Risk of sick leave associated with outdoor air supply rate, humidification, and occupant complaints, Indoor Air. 10 (2000) 212-221. 
[12] M.J. Mendell, E.A. Eliseeva, M.M. Davies, M. Spears, A. Lobscheid, W.J. Fisk, et al., Association of classroom ventilation with reduced illness absence: a prospective study in California elementary schools, Indoor Air. 23 (2013) 515-528. doi:10.1111/ina.12042.

[13] ASHRAE, Standard 62.1-2013 Ventilation for Acceptable Indoor Air Quality, (2013).

[14] M. Santamouris, F. Allard, Natural Ventilation in Buildings: A Design Handbook, Earthscan, 1998.

[15] R.J. de Dear, G.S. Brager, Thermal comfort in naturally ventilated buildings: revisions to ASHRAE Standard 55, Energy Build. 34 (2002) 549-561. doi:10.1016/S0378-7788(02)00005-1.

[16] E. Shaviv, A. Yezioro, I.G. Capeluto, Thermal mass and night ventilation as passive cooling design strategy, Renew. Energy. 24 (2001) 445-452. doi:10.1016/S0960-1481(01)00027-1.

[17] W.W. Nazaroff, G.R. Cass, Mathematical modeling of chemically reactive pollutants in indoor air, Environ. Sci. Technol. 20 (1986) 924-934. doi:10.1021/es00151a012.

[18] A. Rackes, M.S. Waring, Do time-averaged, whole-building, effective volatile organic compound (VOC) emissions depend on the air exchange rate? A statistical analysis of trends for 46 VOCs in U.S. offices, Indoor Air. (2015). doi:10.1111/ina.12224.

[19] C.J. Weschler, H.C. Shields, The Influence of Ventilation on Reactions Among Indoor Pollutants: Modeling and Experimental Observations, Indoor Air. 10 (2000) 92-100. doi:10.1034/j.16000668.2000.010002092.x.

[20] L.E. Ekberg, Concentrations of NO2 and other traffic related contaminants in office buildings located in urban environments, Build. Environ. 30 (1995) 293-298. doi:10.1016/0360-1323(94)00040-Y.

[21] L. Morawska, A. Afshari, G.N. Bae, G. Buonanno, C.Y.H. Chao, O. Hänninen, et al., Indoor aerosols: from personal exposure to risk assessment, Indoor Air. 23 (2013) 462-487. doi:10.1111/ina.12044.

[22] T.N. Quang, C. He, L. Morawska, L.D. Knibbs, Influence of ventilation and filtration on indoor particle concentrations in urban office buildings, Atmos. Environ. 79 (2013) 41-52. doi:10.1016/j.atmosenv.2013.06.009.

[23] C.J. Weschler, Ozone in Indoor Environments: Concentration and Chemistry, Indoor Air. 10 (2000) 269-288. doi:10.1034/j.1600-0668.2000.010004269.x.

[24] A. Rackes, M.S. Waring, Modeling impacts of dynamic ventilation strategies on indoor air quality of offices in six US cities, Build. Environ. 60 (2013) 243-253. doi:10.1016/j.buildenv.2012.10.013.

[25] N.E. Klepeis, W.C. Nelson, W.R. Ott, J.P. Robinson, A.M. Tsang, P. Switzer, et al., The National Human Activity Pattern Survey (NHAPS): a resource for assessing exposure to environmental pollutants, J. Expo. Anal. Environ. Epidemiol. 11 (2001) 231-252. doi:10.1038/sj.jea.7500165.

[26] L. Wallace, A decade of studies of human exposure: what have we learned?, Risk Anal. Off. Publ. Soc. Risk Anal. 13 (1993) 135-139.

[27] L.A. Wallace, Comparison of risks from outdoor and indoor exposure to toxic chemicals., Environ. Health Perspect. 95 (1991) 7-13.

[28] L. Wallace, Indoor Particles: A Review, J. Air Waste Manag. Assoc. 46 (1996) 98-126. doi:10.1080/10473289.1996.10467451.

[29] C.J. Weschler, Ozone's impact on public health: contributions from indoor exposures to ozone and products of ozone-initiated chemistry, Environ. Health Perspect. 114 (2006) 1489-1496.

[30] D.W. Dockery, C.A. Pope, Acute Respiratory Effects of Particulate Air Pollution, Annu. Rev. Public Health. 15 (1994) 107-132. doi:10.1146/annurev.pu.15.050194.000543.

[31] D.W. Dockery, J. Schwartz, J.D. Spengler, Air pollution and daily mortality: Associations with particulates and acid aerosols, Environ. Res. 59 (1992) 362-373. doi:10.1016/S0013-9351(05)80042-8.

[32] Dominici F, Peng RD, Bell ML, et al, FIne particulate air pollution and hospital admission for cardiovascular and respiratory diseases, JAMA. 295 (2006) 1127-1134. doi:10.1001/jama.295.10.1127.

[33] Pope, Burnett, Thun, et al, Lung cancer, cardiopulmonary mortality, and long-term exposure to fine particulate air pollution, JAMA. 287 (2002) 1132-1141. doi:10.1001/jama.287.9.1132.

[34] C.A. Pope, D.W. Dockery, J. Schwartz, Review of Epidemiological Evidence of Health Effects of Particulate Air Pollution, Inhal. Toxicol. 7 (1995) 1-18. doi:10.3109/08958379509014267. 
[35] C.A. Pope, R.T. Burnett, D. Krewski, M. Jerrett, Y. Shi, E.E. Calle, et al., Cardiovascular Mortality and Exposure to Airborne Fine Particulate Matter and Cigarette Smoke Shape of the ExposureResponse Relationship, Circulation. 120 (2009) 941-948. doi:10.1161/CIRCULATIONAHA.109.857888.

[36] J. Schwartz, D.W. Dockery, L.M. Neas, Is Daily Mortality Associated Specifically with Fine Particles?, J. Air Waste Manag. Assoc. 46 (1996) 927-939. doi:10.1080/10473289.1996.10467528.

[37] M.L. Bell, R.D. Peng, F. Dominici, The exposure-response curve for ozone and risk of mortality and the adequacy of current ozone regulations, Environ. Health Perspect. 114 (2006) 532-536.

[38] M.L. Bell, M. A, Zeger SL, Samet JM, Dominici F, OZone and short-term mortality in 95 us urban communities, 1987-2000, JAMA. 292 (2004) 2372-2378. doi:10.1001/jama.292.19.2372.

[39] G. Bylin, T. Lindvall, T. Rehn, B. Sundin, Effects of short-term exposure to ambient nitrogen dioxide concentrations on human bronchial reactivity and lung function, Eur. J. Respir. Dis. 66 (1985) 205-217.

[40] J.M. Logue, P.N. Price, M.H. Sherman, B.C. Singer, A Method to Estimate the Chronic Health Impact of Air Pollutants in U.S. Residences, Environ. Health Perspect. 120 (2012) 216-222. doi:10.1289/ehp.1104035.

[41] H. Guo, S.C. Lee, L.Y. Chan, W.M. Li, Risk assessment of exposure to volatile organic compounds in different indoor environments, Environ. Res. 94 (2004) 57-66. doi:10.1016/S00139351(03)00035-5.

[42] G. Bekö, G. Clausen, C.J. Weschler, Is the use of particle air filtration justified? Costs and benefits of filtration with regard to health effects, building cleaning and occupant productivity, Build. Environ. 43 (2008) 1647-1657. doi:10.1016/j.buildenv.2007.10.006.

[43] Z. El Orch, B. Stephens, M.S. Waring, Predictions and determinants of size-resolved particle infiltration factors in single-family homes in the U.S., Build. Environ. 74 (2014) 106-118. doi:10.1016/j.buildenv.2014.01.006.

[44] W.J. Fisk, D. Faulkner, J. Palonen, O. Seppanen, Performance and costs of particle air filtration technologies, Indoor Air. 12 (2002) 223-234. doi:10.1034/j.1600-0668.2002.01136.x.

[45] O.O. Hänninen, J. Palonen, J.T. Tuomisto, T. Yli-Tuomi, O. Seppänen, M.J. Jantunen, Reduction potential of urban PM2.5 mortality risk using modern ventilation systems in buildings, Indoor Air. 15 (2005) 246-256. doi:10.1111/j.1600-0668.2005.00365.x.

[46] W.J. Riley, T.E. McKone, A.C.K. Lai, W.W. Nazaroff, Indoor Particulate Matter of Outdoor Origin: Importance of Size-Dependent Removal Mechanisms, Environ. Sci. Technol. 36 (2002) 200-207. doi:10.1021/es010723y.

[47] M.S. Waring, J.A. Siegel, Particle loading rates for HVAC filters, heat exchangers, and ducts, Indoor Air. 18 (2008) 209-224. doi:10.1111/j.1600-0668.2008.00518.x.

[48] M.S. Waring, J.A. Siegel, The influence of HVAC systems on indoor secondary organic aerosol formation, ASHRAE Trans. 116 (2010) 556-571.

[49] Z. Tong, Y. Chen, A. Malkawi, G. Adamkiewicz, J.D. Spengler, Quantifying the impact of trafficrelated air pollution on the indoor air quality of a naturally ventilated building, Environ. Int. 89-90 (2016) 138-146. doi:10.1016/j.envint.2016.01.016.

[50] U.S. DOE, EnergyPlusEngineering Reference: The Reference to EnergyPlus Calculations (in case you want or need to know), (2013).

[51] U.S. DOE, Input Output Reference: An Encyclopedic Reference to EnergyPlus Inputs and Outputs. U.S. Department of Energy, (2013).

[52] U.S. EPA, AirData website File Download page, (n.d.). http://aqsdr1.epa.gov/aqsweb/aqstmp/airdata/download_files.html (accessed April 24, 2015).

[53] U.S. EIA, Commercial Buildings Energy Consumption Survey, U.S. Energy Information Administration, 2015.

[54] U.S. EPA, Building Assessment Survey and Evaluation Study, E.S. Environmental Protection Agency, n.d. http://www.epa.gov/indoor-air-quality-iaq/building-assessment-survey-and-evaluationstudy (accessed February 4, 2016). 
[55] M.V. Swami, S. Chandra, Procedures for Calculating Natural Ventilation Airflow Rates in Buildings, ASHRAE, 1987.

[56] ASHRAE, NSI/ASHRAE/IES Standard 90.1-2013 -- Energy Standard for Buildings Except LowRise Residential Buildings, Am. Soc. Heat. Refrig. Air-Cond. Eng. Inc. (2013).

[57] U.S. DOE, Guide to Determining Climate Regions by County, Volume 7.3, (2015).

[58] U.S. DOE, EnergyPlus: Weather Data, (n.d.). https://energyplus.net/weather (accessed April 8, 2015).

[59] U.S. DOE, EnergyPlus Energy Simulation Software: Add-Ons., (n.d.). http://apps1.eere.energy.gov/buildings/energyplus/energyplus_addons.cfm/ (accessed April 6, 2015).

[60] C.K. Wilkins, M.H. Hosni, Plug Load Design Factors, ASHRAE J. 53 (2011) 30-32,34.

[61] W.W. Nazaroff, Indoor particle dynamics, Indoor Air. 14 Suppl 7 (2004) 175-183. doi:10.1111/j.1600-0668.2004.00286.x.

[62] K. Belanger, J.F. Gent, E.W. Triche, M.B. Bracken, B.P. Leaderer, Association of indoor nitrogen dioxide exposure with respiratory symptoms in children with asthma, Am. J. Respir. Crit. Care Med. 173 (2006) 297-303. doi:10.1164/rccm.200408-11230C.

[63] V.J. Cogliano, Y. Grosse, R.A. Baan, K. Straif, M.B. Secretan, F. El Ghissassi, et al., Meeting report: summary of IARC monographs on formaldehyde, 2-butoxyethanol, and 1-tert-butoxy-2propanol, Environ. Health Perspect. 113 (2005) 1205-1208.

[64] J.G. Allen, P. MacNaughton, U. Satish, S. Santanam, J. Vallarino, J.D. Spengler, Associations of Cognitive Function Scores with Carbon Dioxide, Ventilation, and Volatile Organic Compound Exposures in Office Workers: A Controlled Exposure Study of Green and Conventional Office Environments, Environ. Health Perspect. (2015). doi:10.1289/ehp.1510037.

[65] M.S. Waring, J.R. Wells, Volatile organic compound conversion by ozone, hydroxyl radicals, and nitrate radicals in residential indoor air: Magnitudes and impacts of oxidant sources, Atmos. Environ. 106 (2015) 382-391. doi:10.1016/j.atmosenv.2014.06.062.

[66] J.R. Girman, M.G. Apte, G.W. Traynor, J.R. Allen, C.D. Hollowell, Pollutant emission rates from indoor combustion appliances and sidestream cigarette smoke, Environ. Int. 8 (1982) 213-221. doi:10.1016/0160-4120(82)90030-7.

[67] S.C. Lee, S. Lam, H. Kin Fai, Characterization of VOCs, ozone, and PM10 emissions from office equipment in an environmental chamber, Build. Environ. 36 (2001) 837-842. doi:10.1016/S03601323(01)00009-9.

[68] B. Stephens, E.T. Gall, J.A. Siegel, Measuring the Penetration of Ambient Ozone into Residential Buildings, Environ. Sci. Technol. 46 (2012) 929-936. doi:10.1021/es2028795.

[69] G. Bekö, G. Clausen, C.J. Weschler, Further studies of oxidation processes on filter surfaces: Evidence for oxidation products and the influence of time in service, Atmos. Environ. 41 (2007) 52025212. doi:10.1016/j.atmosenv.2006.07.063.

[70] C.P. Weisel, J. Zhang, B.J. Turpin, M.T. Morandi, S. Colome, T.H. Stock, et al., Relationships of Indoor, Outdoor, and Personal Air (RIOPA). Part I. Collection methods and descriptive analyses., Res. Rep. Health Eff. Inst. (2005) 1-107; discussion 109-27.

[71] E.L. Hult, H. Willem, P.N. Price, T. Hotchi, M.L. Russell, B.C. Singer, Formaldehyde and acetaldehyde exposure mitigation in US residences: in-home measurements of ventilation control and source control, Indoor Air. 25 (2015) 523-535. doi:10.1111/ina.12160.

[72] P. Azimi, D. Zhao, B. Stephens, Estimates of HVAC filtration efficiency for fine and ultrafine particles of outdoor origin, Atmos. Environ. 98 (2014) 337-346. doi:10.1016/j.atmosenv.2014.09.007.

[73] S. Youssefi, M.S. Waring, Transient secondary organic aerosol formation from limonene ozonolysis in indoor environments: impacts of air exchange rates and initial concentration ratios, Environ. Sci. Technol. 48 (2014) 7899-7908. doi:10.1021/es5009906.

[74] S. Youssefi, M.S. Waring, Indoor transient SOA formation from ozone $+\alpha$-pinene reactions: Impacts of air exchange and initial product concentrations, and comparison to limonene ozonolysis, Atmos. Environ. 112 (2015) 106-115. doi:10.1016/j.atmosenv.2015.04.001. 
[75] M.S. Waring, Secondary organic aerosol in residences: predicting its fraction of fine particle mass and determinants of formation strength, Indoor Air. 24 (2014) 376-389. doi:10.1111/ina.12092.

[76] M.S. Waring, J.R. Wells, J.A. Siegel, Secondary organic aerosol formation from ozone reactions with single terpenoids and terpenoid mixtures, Atmos. Environ. 45 (2011) 4235-4242. doi:10.1016/j.atmosenv.2011.05.001.

[77] Y. Yang, M.S. Waring, Secondary organic aerosol formation initiated by $\alpha$-terpineol ozonolysis in indoor air, Indoor Air. (2016) n/a-n/a. doi:10.1111/ina.12271.

[78] A.M. Johnson, M.S. Waring, P.F. DeCarlo, Real-time transformation of outdoor aerosol components upon transport indoors measured with aerosol mass spectrometry, Indoor Air. (2016). doi:10.1111/ina.12299.

[79] S.M. Dutton, D. Banks, S.L. Brunswick, W.J. Fisk, Health and economic implications of natural ventilation in California offices, Build. Environ. 67 (2013) 34-45. doi:10.1016/j.buildenv.2013.05.002.

[80] R.T. Burnett, M. Smith-doiron, D. Stieb, S. Cakmak, J.R. Brook, Effects of Particulate and Gaseous Air Pollution on Cardiorespiratory Hospitalizations, Arch. Environ. Health Int. J. 54 (1999) 130139. doi:10.1080/00039899909602248. 
(a)

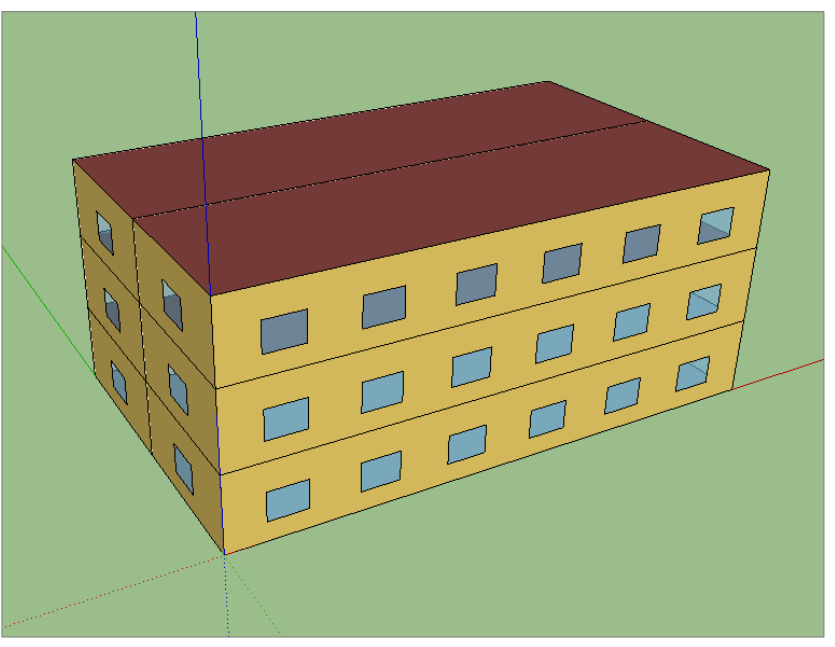

(b)

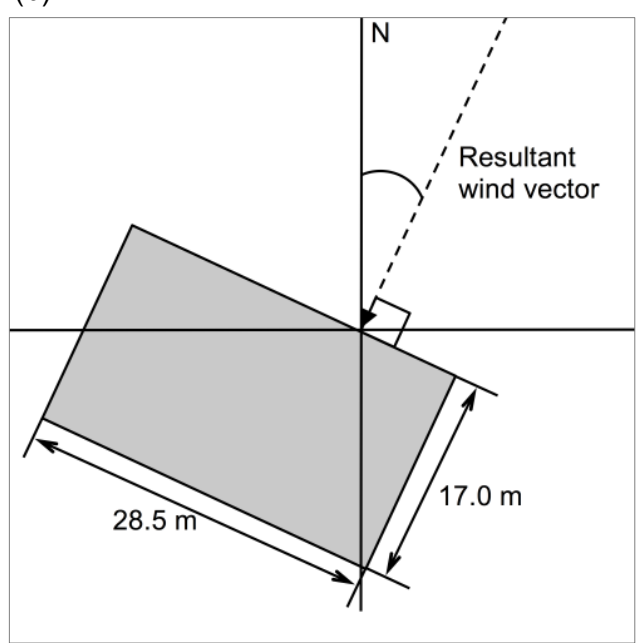

Figure 1. (a) Model visualization of standard office building, and (b) example of building orientation with respect to resultant wind direction. 


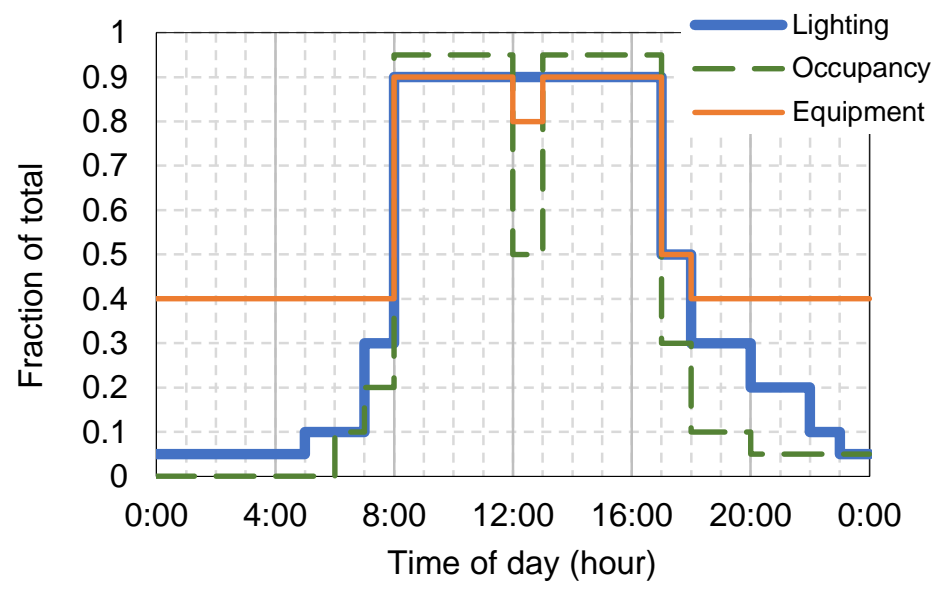

Figure 2. Internal load schedules during a typical workday used in energy modeling. 

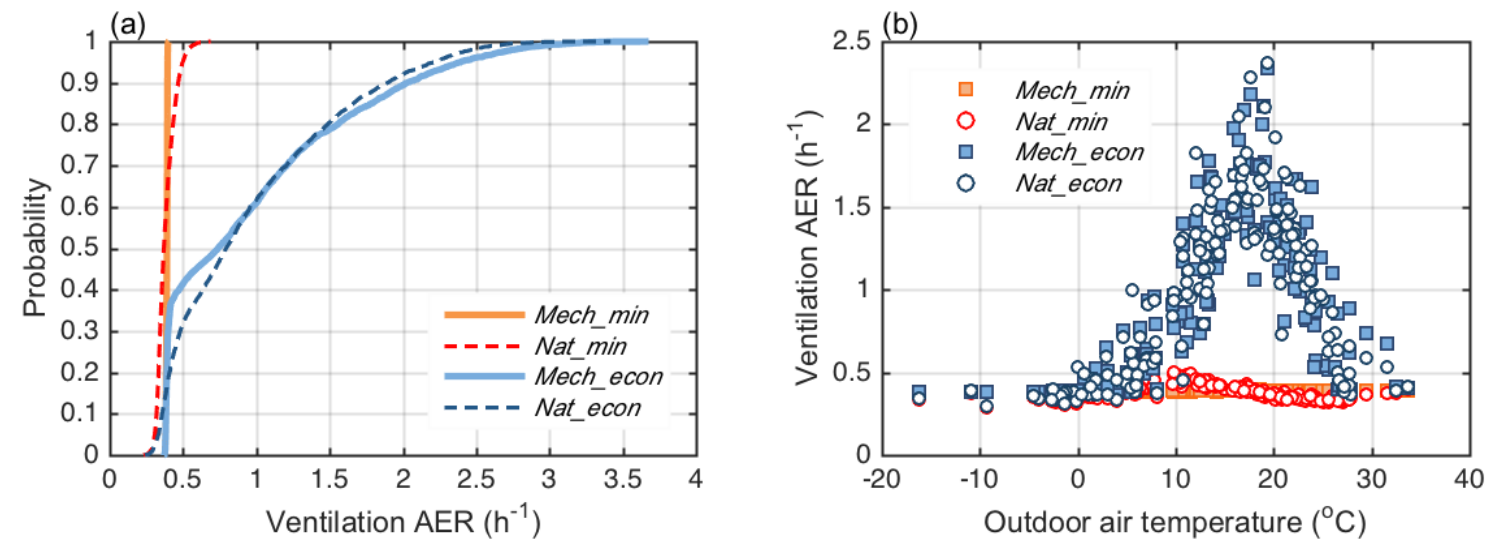

Figure 3. (a) Cumulative distribution function of mean daily ventilation air exchange rate and (b) mean monthly ventilation air exchange rate (AER) as a function of mean monthly outdoor air temperature under the four ventilation strategies. 


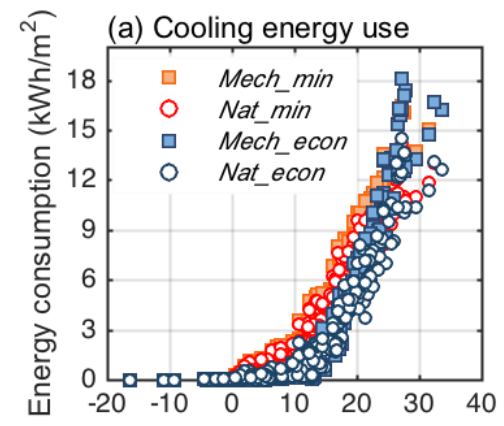

(b) Heating energy use

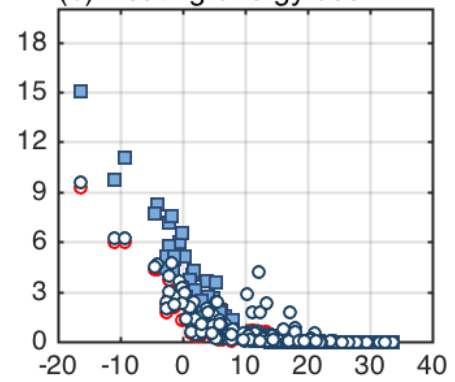

6 (e) Heating energy savings

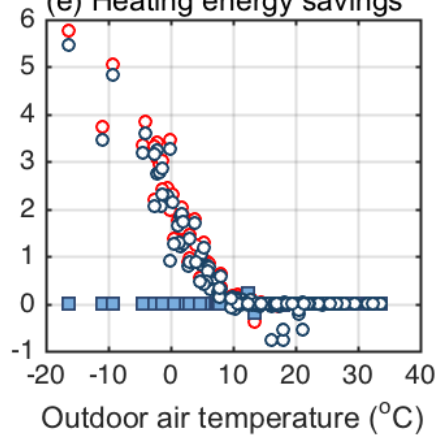

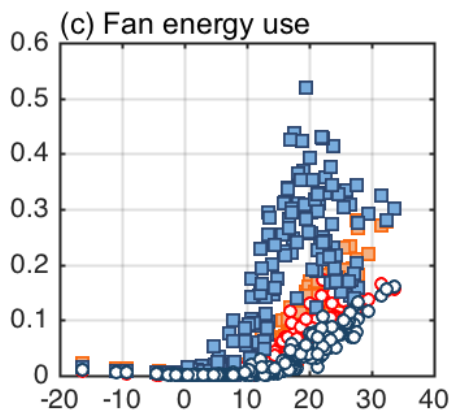

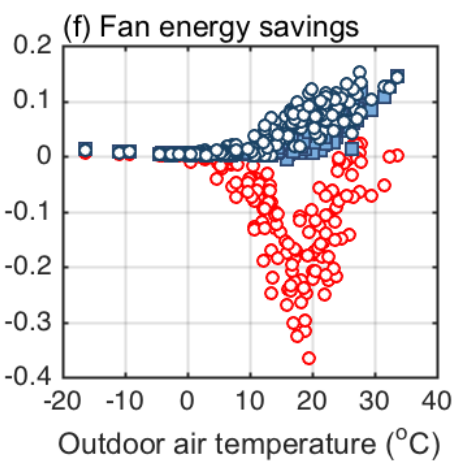

Figure 4. (a-c) Ideal system monthly energy consumption as a function of mean monthly outdoor air temperature under the four ventilation strategies, as well as (d-f) energy savings compared to Mech_min. 

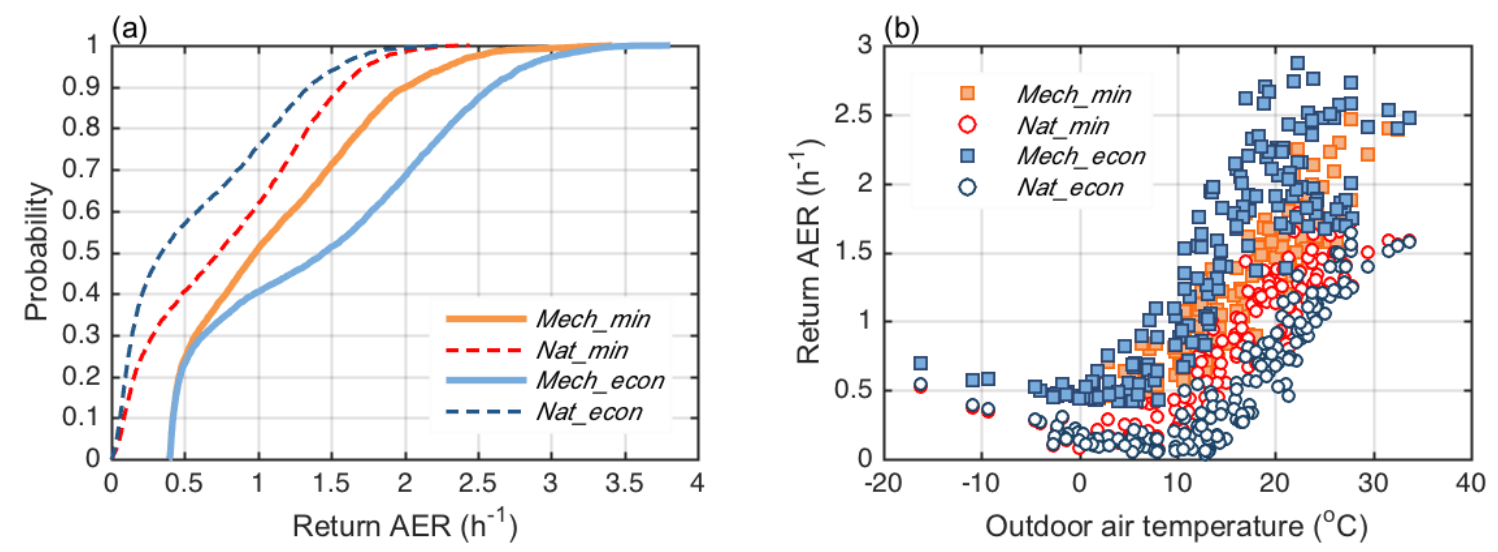

Figure 5. (a) Cumulative distribution function of mean daily recirculation air exchange rate and (b) mean monthly return air exchange rate (AER) as a function of mean monthly outdoor air temperature under the four ventilation strategies. 
(a) AER-dependent (best estimate)

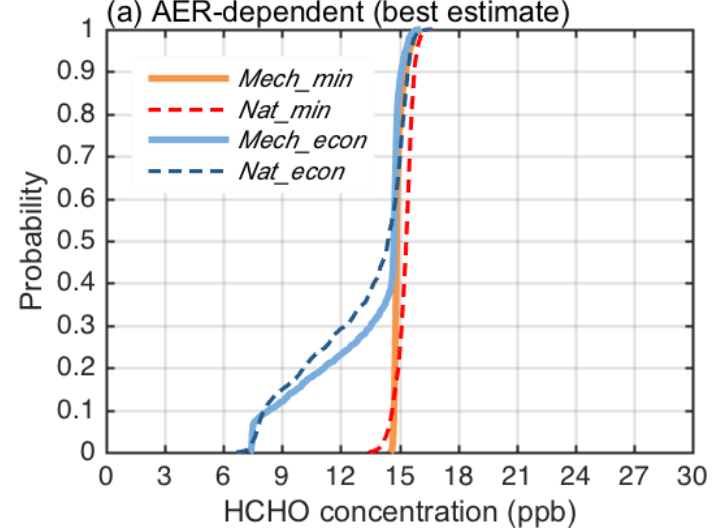

(b) AER-independent

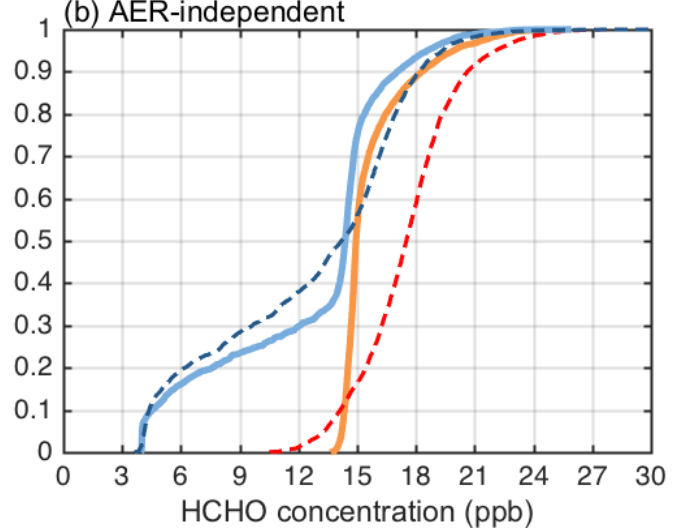

Figure 6. Cumulative distribution functions of indoor $\mathrm{HCHO}$ concentrations under four ventilation strategies, simulated in Philadelphia, PA (climate zone 4A) for (a) the best estimate AER-dependent emissions model with $k L=1.6 \mathrm{~h}^{-1}$ and (b) the AER-independent emissions model with $k L=0.05 \mathrm{~h}^{-1}$. See text for details about $\mathrm{HCHO}$ emission models from Rackes and Waring [18]. 

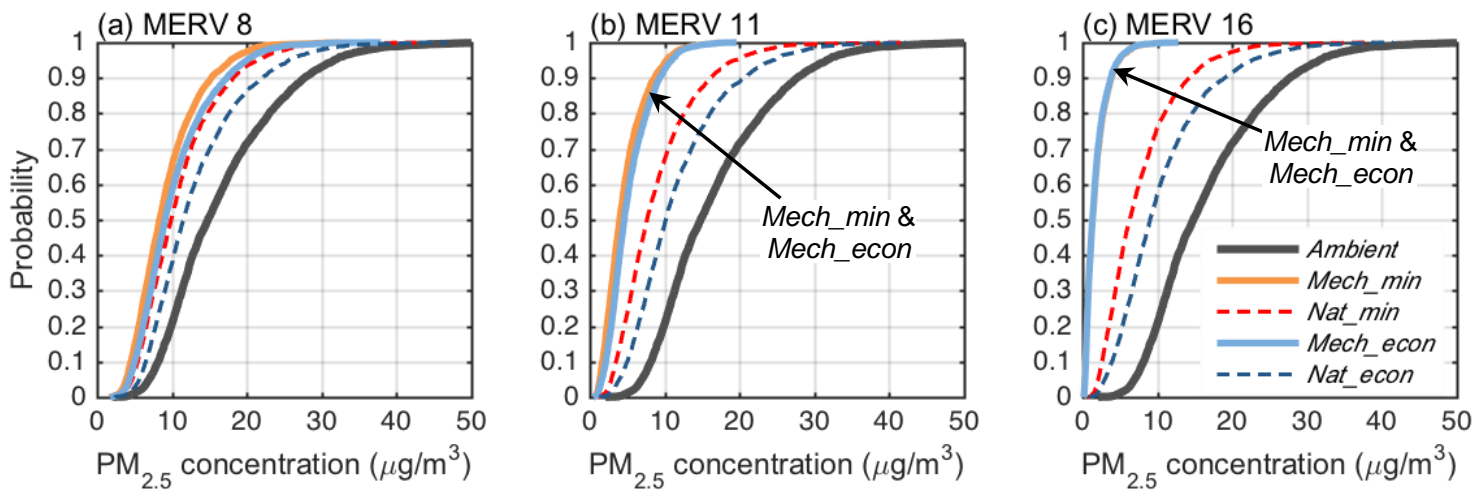

Figure 7. Cumulative distribution functions of ambient $\mathrm{PM}_{2.5}$ and indoor $\mathrm{PM}_{2.5}$ concentrations under four ventilation strategies simulated in Philadelphia, PA (climate region 4A) using filters with efficiencies of (a) MERV 8, (b) MERV 11, and (c) MERV 16. 
(a) $\mathrm{CO}_{2}$
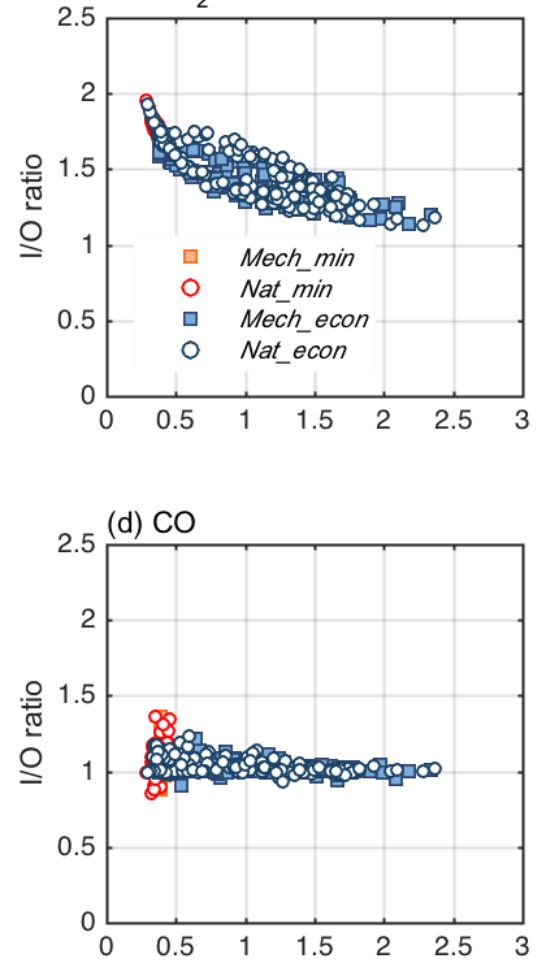

(g) $\mathrm{PM}_{2.5}$, MERV 8

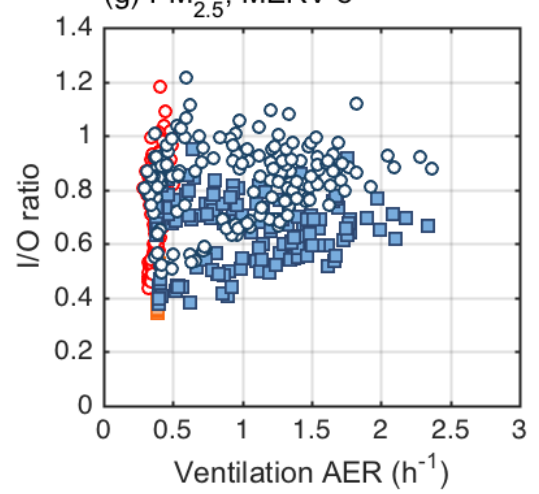

(b) $\mathrm{HCHO}, \mathrm{AER}$-dependent

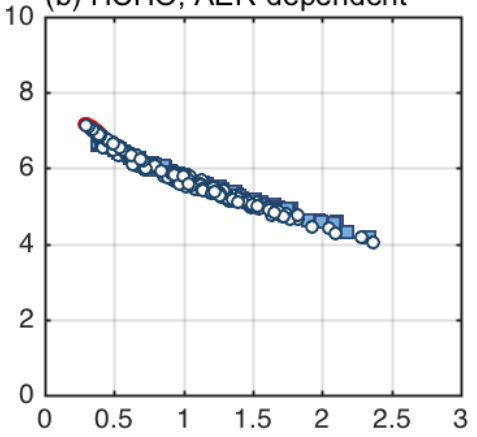

(e) $\mathrm{O}_{3}$

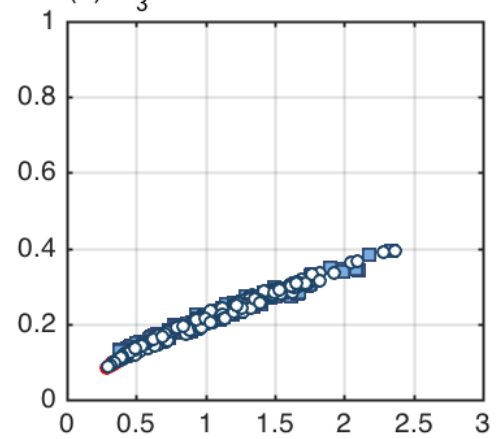

(h) $\mathrm{PM}_{2.5}, \mathrm{MERV} 11$

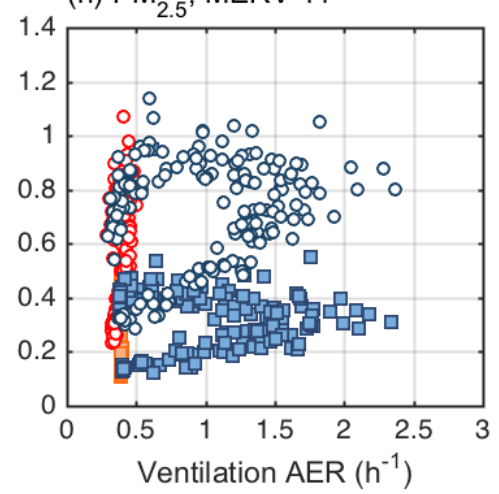

(c) $\mathrm{HCHO}, \mathrm{AER}$-independent

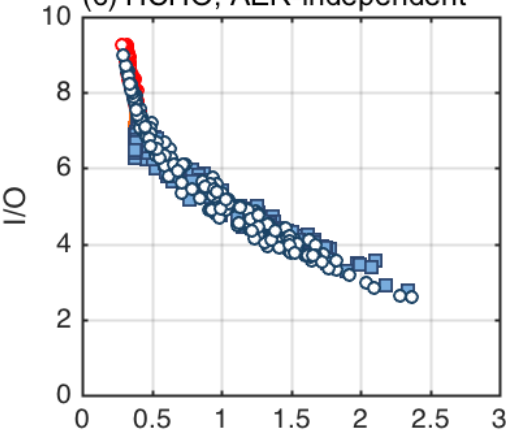

(f) $\mathrm{NO}_{2}$

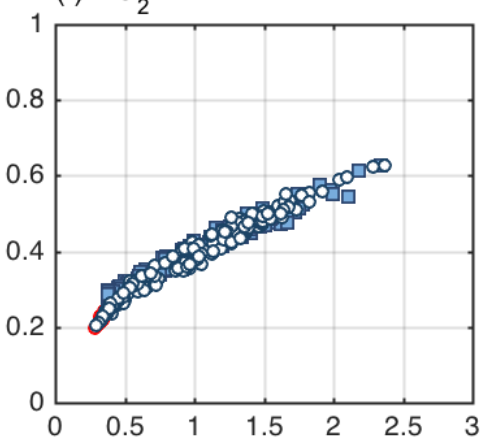

(i) $\mathrm{PM}_{2.5}$, MERV 16

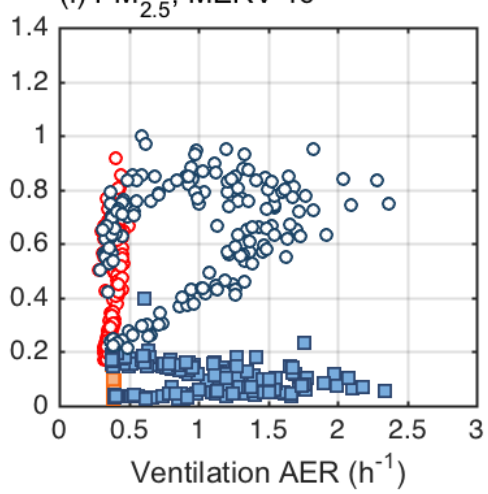

Figure 8. Mean monthly $\mathrm{I} / \mathrm{O}$ ratios as a function of mean monthly ventilation $\mathrm{AER}$, for (a) $\mathrm{CO}_{2} ; \mathrm{HCHO}$ with emissions model set at (b) best estimate of $k L=1.6 \mathrm{~h}^{-1}$ and (c) $k L=0.05 \mathrm{~h}^{-1}$; (d) $\mathrm{CO}$; (e) $\mathrm{O}_{3}$; (f) $\mathrm{NO}_{2}$; and $\mathrm{PM}_{2.5}$ with filters of efficiencies (g) MERV 8, (h) MERV 11, and (i) MERV 16. For (a-c, e, f) data points for minimum strategies are behind data points for economizing strategies on the plots. See text for details about $\mathrm{HCHO}$ emission models from Rackes and Waring [18]. 
(a) $\mathrm{CO}_{2}$

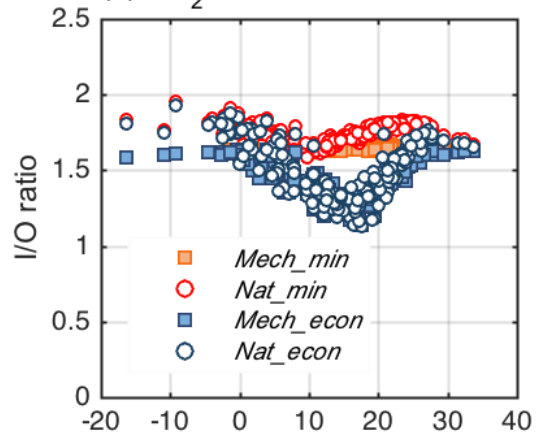

(d) $\mathrm{CO}$

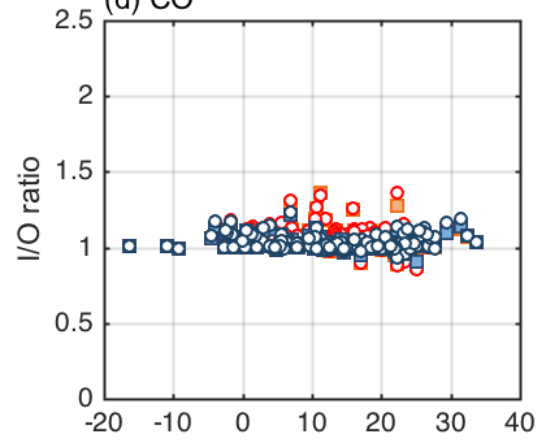

(g) $\mathrm{PM}_{2.5}$, MERV 8

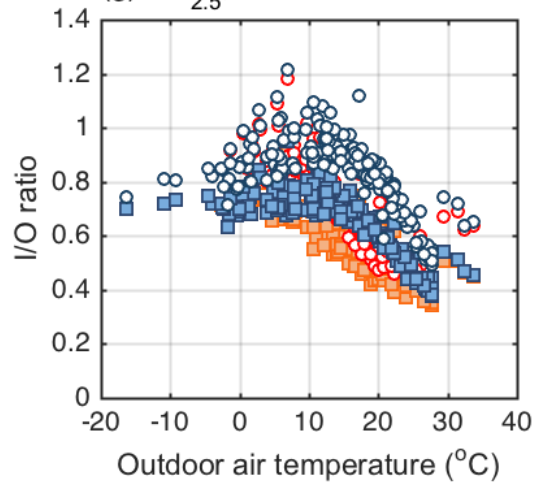

(b) $\mathrm{HCHO}$, AER-dependent

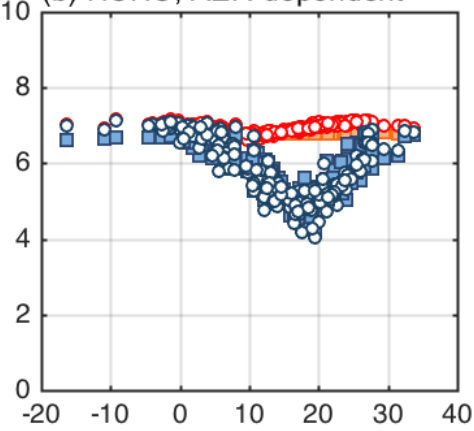

(e) $\mathrm{O}_{3}$

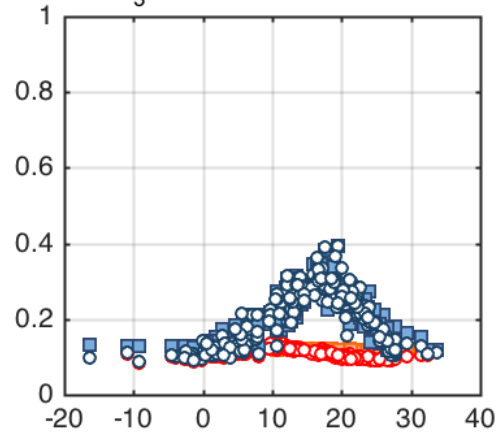

(h) $\mathrm{PM}_{25}$, MERV 11

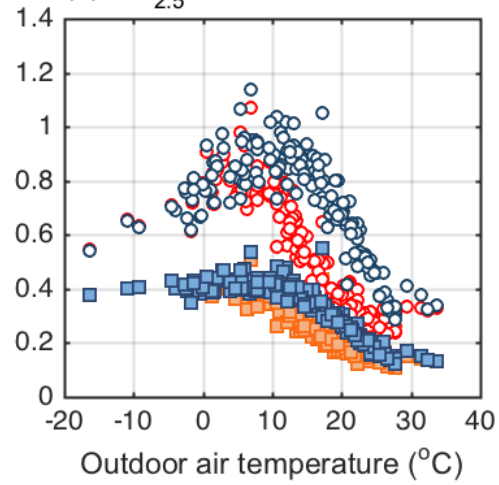

(c) $\mathrm{HCHO}, \mathrm{AER}$-independent
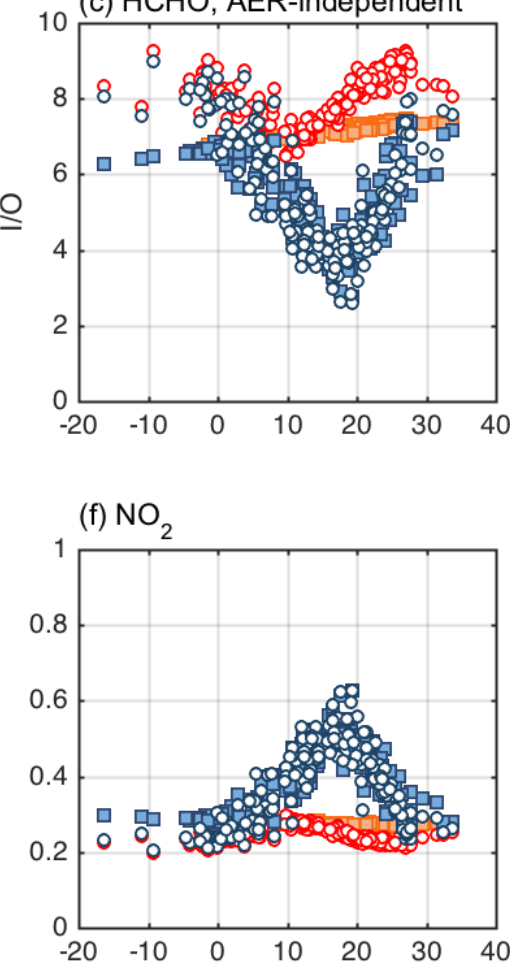

(i) $\mathrm{PM}_{2.5}, \mathrm{MERV} 16$

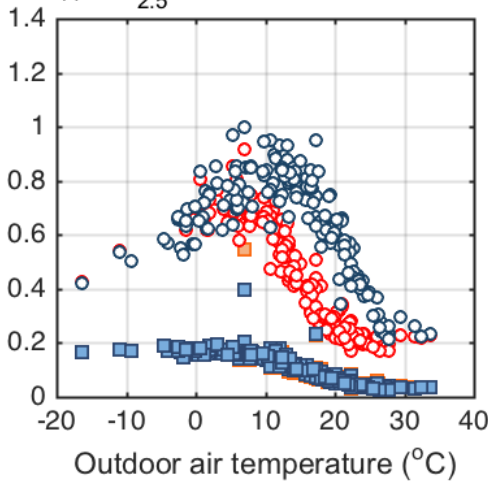

Figure 9. Mean monthly $\mathrm{I} / \mathrm{O}$ ratios as a function of mean monthly outdoor air temperature, for (a) $\mathrm{CO}_{2}$; $\mathrm{HCHO}$ with emissions model set at (b) best estimate of $k L=1.6 \mathrm{~h}^{-1}$ and (c) $k L=0.05 \mathrm{~h}^{-1}$; (d) CO; (e) $\mathrm{O}_{3}$; (f) $\mathrm{NO}_{2}$; and $\mathrm{PM}_{2.5}$ with filters of efficiencies (g) MERV 8, (h) MERV 11, and (i) MERV 16. See text for details about $\mathrm{HCHO}$ emission models from Rackes and Waring [18]. 
Table 1. Simulated representative city in each climate zone, along with the building overall thermal resistive values and wind information for each location.

\begin{tabular}{llllll}
\hline $\begin{array}{l}\text { Climate } \\
\text { Zone }\end{array}$ & City & $\begin{array}{l}\text { Wall R-value } \\
\left(\mathbf{m}^{\mathbf{2}} \mathbf{~} / \mathbf{W}\right)\end{array}$ & $\begin{array}{l}\text { Roof R-value } \\
\left(\mathbf{m}^{\mathbf{2}} \mathbf{K} / \mathbf{W}\right)\end{array}$ & $\begin{array}{l}\text { Mean wind } \\
\mathbf{s p e e d}(\mathbf{m} / \mathbf{s})\end{array}$ & $\begin{array}{l}\text { Resultant wind } \\
\text { direction }\left({ }^{\mathbf{1}} \mathbf{1}^{\mathbf{1}}\right.\end{array}$ \\
\hline 1A & Miami, FL & 2.3 & 5.3 & 3.9 & 105 \\
2A & Houston, TX & 2.3 & 5.3 & 4.6 & 138 \\
2B & Phoenix, AZ & 2.3 & 5.3 & 3.0 & 149 \\
3A & Atlanta, GA & 2.3 & 5.3 & 4.0 & 310 \\
3B & El Paso, TX & 2.3 & 5.3 & 4.0 & 234 \\
3C & Los Angeles, CA & 2.3 & 5.3 & 3.3 & 247 \\
4A & Philadelphia, PA & 2.3 & 6.7 & 4.3 & 275 \\
4B & Albuquerque, NM & 2.3 & 6.7 & 3.9 & 181 \\
4C & Seattle, WA & 3.5 & 6.7 & 4.1 & 193 \\
5A & Boston, MA & 3.5 & 6.7 & 5.9 & 283 \\
5B & Salt Lake City, UT & 3.5 & 6.7 & 4.0 & 174 \\
6A & Milwaukee, WI & 3.5 & 8.6 & 5.1 & 255 \\
6B & Billings, MT & 3.5 & 8.6 & 5.5 & 262 \\
7B & Fargo, ND & 3.7 & 8.6 & 5.8 & 240 \\
\hline
\end{tabular}

1. Wind direction measured clockwise from true north 
Table 2. Sources and losses of each indoor pollutant. Symbols are defined in text.

\begin{tabular}{|c|c|c|}
\hline Pollutant & Sources & Losses \\
\hline Carbon dioxide $\left(\mathrm{CO}_{2}\right)$ & $\frac{E_{\mathrm{p}, \mathrm{CO}_{2}}}{V_{\mathrm{z}}} P_{\mathrm{z}}+C_{\mathrm{CO}_{2}, \text { out }}\left(\lambda_{\mathrm{v}}+\lambda_{\mathrm{i}}\right)$ & $\lambda_{\mathrm{v}}+\lambda_{\mathrm{i}}$ \\
\hline Carbon monoxide (CO) & $C_{\mathrm{CO}, \text { out }}\left(\lambda_{\mathrm{v}}+\lambda_{\mathrm{i}}\right)$ & $\lambda_{\mathrm{v}}+\lambda_{\mathrm{i}}$ \\
\hline Nitrogen dioxide $\left(\mathrm{NO}_{2}\right)$ & $C_{\mathrm{NO}_{2}, \text { out }}\left(\lambda_{\mathrm{v}}+\lambda_{\mathrm{i}}\right)$ & $\lambda_{\mathrm{v}}+\lambda_{\mathrm{i}}+\beta_{\mathrm{NO}_{2}}$ \\
\hline Ozone $\left(\mathrm{O}_{3}\right)$ & $C_{\mathrm{O}_{3}, \text { out }} \lambda_{\mathrm{v}}\left(1-\eta_{\mathrm{v}, \mathrm{O}_{3}}\right)+C_{\mathrm{O}_{3}, \text { out }} p_{\mathrm{O}_{3}} \lambda_{\mathrm{i}}$ & $\lambda_{\mathrm{r}} \eta_{\mathrm{r}, \mathrm{O}_{3}}+\beta_{\mathrm{O}_{3}}+\lambda_{\mathrm{v}}+\lambda_{\mathrm{i}}$ \\
\hline Formaldehyde $(\mathrm{HCHO})$ & $\frac{E_{\mathrm{z}, \mathrm{HCHO}}}{V_{\mathrm{z}}} A_{\mathrm{z}}+\frac{E_{\mathrm{p}, \mathrm{HCHO}}}{V_{\mathrm{z}}} P_{\mathrm{z}}+C_{\mathrm{HCHO}, \text { out }}\left(\lambda_{\mathrm{v}}+\lambda_{\mathrm{i}}\right)$ & $\lambda_{\mathrm{v}}+\lambda_{\mathrm{i}}$ \\
\hline Fine particles $\left(\mathrm{PM}_{2.5}\right)$ & $C_{\mathrm{PM}_{2.5}, \text { out }} \lambda_{\mathrm{v}}\left(1-\eta_{\mathrm{v}, \mathrm{PM}_{2.5}}\right)+C_{\mathrm{PM}_{2.5}, \text { out }} p_{\mathrm{PM}_{2.5}} \lambda_{\mathrm{i}}$ & $\lambda_{\mathrm{r}} \eta_{\mathrm{r}, \mathrm{PM}}{ }_{2.5}+\beta_{\mathrm{PM}_{2.5}}+\lambda_{\mathrm{v}}+\lambda_{\mathrm{i}}$ \\
\hline
\end{tabular}


Table 3. Median (5th, 95th) percentiles of day-mean ventilation air exchange rates (AER) and root mean square error (RMSE) between analogue minimum strategies and correlations (corr) between analogue economizing strategies by location

\begin{tabular}{llllllll}
\hline \multirow{2}{*}{ Climate } & & \multicolumn{2}{l}{ Minimum AER $\left(\mathbf{h}^{-1}\right)$} & \multicolumn{3}{c}{ Economizing AER $\left(\mathbf{h}^{-1}\right)$} \\
Zone & City & Mech_min & Nat_min & RMSE & Mech_econ & Nat_econ & corr \\
\hline 1A & Miami, FL & $0.39(0.39,0.39)$ & $0.33(0.30,0.41)$ & 0.064 & $0.40(0.39,2.3)$ & $0.78(0.34,2.4)$ & 0.81 \\
2A & Houston, TX & $0.39(0.38,0.40)$ & $0.36(0.32,0.53)$ & 0.069 & $0.50(0.39,2.0)$ & $0.80(0.36,2.1)$ & 0.83 \\
2B & Phoenix, AZ & $0.39(0.39,0.40)$ & $0.38(0.34,0.50)$ & 0.051 & $1.0(0.39,2.2)$ & $0.90(0.37,1.9)$ & 0.96 \\
3A & Atlanta, GA & $0.39(0.38,0.39)$ & $0.38(0.31,0.53)$ & 0.078 & $0.62(0.38,2.2)$ & $0.90(0.40,2.2)$ & 0.81 \\
3B & El Paso, TX & $0.39(0.38,0.39)$ & $0.37(0.32,0.51)$ & 0.065 & $1.0(0.40,2.6)$ & $0.78(0.41,2.0)$ & 0.89 \\
3C & Los Angeles, CA & $0.39(0.39,0.39)$ & $0.39(0.32,0.46)$ & 0.045 & $1.4(0.58,2.7)$ & $1.6(0.68,2.6)$ & 0.93 \\
4A & Philadelphia, PA & $0.39(0.38,0.39)$ & $0.36(0.31,0.51)$ & 0.066 & $0.40(0.38,2.2)$ & $0.67(0.34,2.3)$ & 0.92 \\
4B & Albuquerque, NM & $0.39(0.38,0.39)$ & $0.38(0.32,0.48)$ & 0.055 & $1.1(0.39,2.4)$ & $0.89(0.41,2.1)$ & 0.97 \\
4C & Seattle, WA & $0.39(0.38,0.39)$ & $0.39(0.32,0.48)$ & 0.049 & $0.46(0.38,2.0)$ & $0.49(0.33,2.0)$ & 0.99 \\
5A & Boston, MA & $0.39(0.38,0.40)$ & $0.36(0.30,0.48)$ & 0.060 & $0.42(0.38,2.4)$ & $0.49(0.31,2.3)$ & 0.92 \\
5B & Salt Lake City, UT & $0.39(0.38,0.39)$ & $0.37(0.32,0.49)$ & 0.054 & $0.74(0.38,2.4)$ & $0.69(0.36,2.0)$ & 0.98 \\
6A & Milwaukee, WI & $0.39(0.38,0.40)$ & $0.37(0.29,0.50)$ & 0.067 & $0.43(0.38,2.5)$ & $0.64(0.31,2.2)$ & 0.81 \\
6B & Billings, MT & $0.39(0.38,0.40)$ & $0.38(0.30,0.51)$ & 0.067 & $0.51(0.38,2.6)$ & $0.58(0.31,2.0)$ & 0.99 \\
7B & Fargo, ND & $0.39(0.38,0.40)$ & $0.35(0.26,0.50)$ & 0.073 & $0.42(0.38,2.4)$ & $0.51(0.27,2.0)$ & 0.97 \\
\hline
\end{tabular}


Table 4. Annual energy summary by location and strategy, as well as percent of time for economizing (econ.) and hybrid system operation.

\begin{tabular}{|c|c|c|c|c|c|c|c|}
\hline \multirow{2}{*}{$\begin{array}{l}\text { Climate } \\
\text { Zone }\end{array}$} & \multirow[b]{2}{*}{ City } & \multirow[b]{2}{*}{ Strategy } & \multicolumn{3}{|c|}{ Energy consumption $\left(\mathrm{kW} / \mathrm{m}^{2}\right)$} & \multirow[b]{2}{*}{$\%$ econ. } & \multirow[b]{2}{*}{$\%$ hybrid } \\
\hline & & & Cooling & Heating & Fan & & \\
\hline \multirow[t]{4}{*}{$1 \mathrm{~A}$} & Miami, FL & Mech_min & 144 & $4.85 \times 10^{-2}$ & 1.55 & - & - \\
\hline & & Nat_min & 117 & $1.75 \times 10^{-2}$ & 1.04 & - & $99 \%$ \\
\hline & & Mech_econ & 137 & $4.85 \times 10^{-2}$ & 2.27 & $17 \%$ & - \\
\hline & & Nat econ & 107 & $2.48 \times 10^{-2}$ & 0.843 & $30 \%$ & $93 \%$ \\
\hline \multirow[t]{4}{*}{$2 \mathrm{~A}$} & Houston, TX & Mech $\min$ & 105 & 1.55 & 1.08 & - & - \\
\hline & & Nat_min & 90.0 & 1.97 & 0.669 & - & $89 \%$ \\
\hline & & Mech_econ & 96.7 & 1.49 & 1.89 & $23 \%$ & - \\
\hline & & Nat econ & 86.0 & 9.22 & 0.484 & $32 \%$ & $75 \%$ \\
\hline \multirow[t]{4}{*}{$2 \mathrm{~B}$} & Phoenix, AZ & Mech min & 111 & 0.711 & 1.64 & - & - \\
\hline & & Nat_min & 92.2 & 0.316 & 1.10 & - & $94 \%$ \\
\hline & & Mech_econ & 92.6 & 0.711 & 3.09 & $35 \%$ & - \\
\hline & & Nat_econ & 75.0 & 0.580 & 0.800 & $35 \%$ & $84 \%$ \\
\hline \multirow[t]{4}{*}{$3 A$} & Atlanta, GA & Mech_min & 71.1 & 6.94 & 0.852 & - & - \\
\hline & & Nat_min & 60.4 & 4.38 & 0.552 & - & $85 \%$ \\
\hline & & Mech_econ & 56.9 & 6.94 & 1.67 & $27 \%$ & - \\
\hline & & Nat_econ & 44.5 & 4.99 & 0.322 & $35 \%$ & $68 \%$ \\
\hline \multirow[t]{4}{*}{$3 B$} & El Paso, TX & Mech_min & 84.3 & 2.16 & 1.42 & - & - \\
\hline & & Nat_min & 73.1 & 0.744 & 0.939 & - & $85 \%$ \\
\hline & & Mech_econ & 65.8 & 2.16 & 2.84 & $35 \%$ & - \\
\hline & & Nat econ & 57.6 & 0.872 & 0.640 & $30 \%$ & $73 \%$ \\
\hline \multirow[t]{4}{*}{$3 C$} & Los Angeles, CA & Mech_min & 61.1 & 0.137 & 0.951 & - & - \\
\hline & & Nat_min & 60.5 & 0.119 & 0.619 & - & $88 \%$ \\
\hline & & Mech_econ & 24.3 & 0.137 & 3.07 & $63 \%$ & - \\
\hline & & Nat_econ & 25.3 & 0.184 & 0.205 & $68 \%$ & $45 \%$ \\
\hline \multirow[t]{4}{*}{$4 \mathrm{~A}$} & Philadelphia, PA & Mech_min & 51.5 & 18.4 & 0.658 & - & - \\
\hline & & Nat_min & 44.2 & 10.5 & 0.423 & - & $81 \%$ \\
\hline & & Mech_econ & 39.3 & 18.4 & 1.51 & $24 \%$ & - \\
\hline & & Nat_econ & 31.0 & 11.2 & 0.264 & $28 \%$ & $67 \%$ \\
\hline \multirow[t]{4}{*}{ 4B } & Albuquerque, NM & Mech_min & 56.7 & 6.22 & 0.909 & - & - \\
\hline & & Nat_min & 51.0 & 1.87 & 0.562 & - & $83 \%$ \\
\hline & & Mech_econ & 35.9 & 6.22 & 2.44 & $40 \%$ & - \\
\hline & & Nat_econ & 32.8 & 2.36 & 0.291 & $38 \%$ & $68 \%$ \\
\hline \multirow[t]{4}{*}{$4 \mathrm{C}$} & Seattle, WA & Mech_min & 22.9 & 13.3 & 0.384 & - & - \\
\hline & & Nat_min & 22.4 & 7.42 & 0.232 & - & $68 \%$ \\
\hline & & Mech_econ & 8.30 & 13.3 & 1.07 & $27 \%$ & - \\
\hline & & Nat_econ & 7.60 & 7.95 & $7.66 \times 10^{-2}$ & $29 \%$ & $45 \%$ \\
\hline \multirow[t]{4}{*}{$5 \mathrm{~A}$} & Boston, MA & Mech_min & 38.2 & 21.4 & 0.640 & - & - \\
\hline & & Nat_min & 35.0 & 10.7 & 0.300 & - & $75 \%$ \\
\hline & & Mech_econ & 24.5 & 21.4 & 1.29 & $23 \%$ & - \\
\hline & & Nat_econ & 20.8 & 11.5 & 0.151 & $26 \%$ & $60 \%$ \\
\hline \multirow[t]{4}{*}{$5 B$} & Salt Lake City, UT & Mech_min & 49.6 & 13.5 & 0.836 & - & - \\
\hline & & Nat_min & 44.2 & 4.87 & 0.570 & - & $77 \%$ \\
\hline & & Mech_econ & 34.2 & 13.5 & 1.84 & $28 \%$ & - \\
\hline & & Nat_econ & 30.1 & 6.37 & 0.329 & $27 \%$ & $64 \%$ \\
\hline $6 \mathrm{~A}$ & Milwaukee, WI & Mech_min & 40.3 & 28.3 & 0.587 & - & - \\
\hline & & Nat_min & 36.6 & 14.2 & 0.338 & - & $77 \%$ \\
\hline & & Mech_econ & 24.9 & 28.3 & 1.42 & $26 \%$ & - \\
\hline & & Nat_econ & 27.6 & 26.5 & 0.269 & $27 \%$ & $65 \%$ \\
\hline $6 \mathrm{~B}$ & Billings, MT & Mech_min & 42.5 & 25.7 & 0.679 & - & - \\
\hline & & Nat_min & 39.2 & 13.8 & 0.563 & - & $73 \%$ \\
\hline & & Mech_econ & 26.6 & 25.7 & 1.85 & $27 \%$ & - \\
\hline & & Nat_econ & 24.0 & 14.6 & 0.282 & $26 \%$ & $61 \%$ \\
\hline $7 \mathrm{~B}$ & Fargo, ND & Mech_min & 41.2 & 47.9 & 0.631 & - & - \\
\hline & & Nat_min & 37.3 & 26.0 & 0.434 & - & $81 \%$ \\
\hline
\end{tabular}




\begin{tabular}{llllll} 
Mech_econ & 26.7 & 47.9 & 1.44 & $24 \%$ & - \\
Nat_econ & 23.0 & 27.3 & 0.217 & $26 \%$ & $67 \%$ \\
\hline
\end{tabular}

Table 5. Indoor $\mathrm{CO}_{2}$ and $\mathrm{HCHO}$ concentration distributions under four ventilation cases, listing the median (5th and 95th) percentiles.

\begin{tabular}{|c|c|c|c|}
\hline \multirow[b]{2}{*}{ Case } & \multirow[b]{2}{*}{$\mathrm{CO}_{2}(\mathrm{ppm})$} & \multicolumn{2}{|l|}{$\mathrm{HCHO}^{1}$ (ppb) } \\
\hline & & $k L=1.6 \mathrm{~h}^{-1}$ & $k L=0.05 \mathrm{~h}^{-1}$ \\
\hline Mech_min & $802(474,925)$ & $14.8(14.7,15.5)$ & $14.9(14.1,19.9)$ \\
\hline Nat_min & $821(478,1040)$ & $15.3(14.5,15.9)$ & $17.4(13.5,22.1)$ \\
\hline Mech_econ & $628(459,905)$ & $14.5(7.31,15.2)$ & $13.8(3.94,18.2)$ \\
\hline Nat_econ & $640(458,989)$ & $14.1(7.65,15.6)$ & $13.4(4.11,19.4)$ \\
\hline
\end{tabular}

1. $\mathrm{HCHO}$ was computed with two emission models, one which assumed emission rates dependent on the ventilation AER (column labeled $k L=1.6 \mathrm{~h}^{-1}$ ) and one which assumed independent emission rates (column labeled $k L=0.05$ $\mathrm{h}^{-1}$ ). The AER-dependent model $\mathrm{HCHO}$ results comprise our best estimate. See text for details about these HCHO emission models, which are from Rackes and Waring [18]. 
Table 6. Indoor CO concentration distribution median (5th and 95th) percentiles in each climate zone. Outdoor concentrations are not provided since they are nearly identical to indoor concentrations, since CO was treated as non-reactive and non-sorptive with no indoor emission.

\begin{tabular}{lll}
\hline $\begin{array}{l}\text { Climate } \\
\text { zone }\end{array}$ & City & CO $(\mathbf{p p m})$ \\
\hline 1A & Miami, FL & $0.23(0.037,0.41)$ \\
2A & Houston, TX & $0.25(0.15,0.54)$ \\
2B & Phoenix, AZ & $0.27(0.10,0.83)$ \\
3A & Atlanta, GA & $0.41(0.20,0.73)$ \\
3B & El Paso, TX & $0.20(0.11,0.57)$ \\
3C & Los Angeles, CA & $0.28(0.17,0.74)$ \\
4A & Philadelphia, PA & $0.24(0.067,0.52)$ \\
4B & Albuquerque, NM & $0.19(0.11,0.43)$ \\
4C & Seattle, WA & $0.21(0.13,0.43)$ \\
5A & Boston, MA & $0.25(0.17,0.47)$ \\
5B & Salt Lake City, UT & $0.25(0.14,0.88)$ \\
6A & Milwaukee, WI & $0.25(0.25,0.27)$ \\
6B & Billings, MT & $0.16(0.00,0.75)$ \\
7B & Fargo, ND & $0.15(0.097,0.22)$ \\
\hline
\end{tabular}


Table 7. Ambient and indoor concentration distribution median (5th and 95th) percentiles for $\mathrm{NO}_{2}, \mathrm{O}_{3}$, and $\mathrm{PM}_{2.5}$ under four ventilation cases in each simulated city.

\begin{tabular}{|c|c|c|c|c|c|c|c|}
\hline \multirow{2}{*}{$\begin{array}{l}\text { Climate } \\
\text { Zone }\end{array}$} & \multirow[t]{2}{*}{ City } & \multirow[t]{2}{*}{ Case } & \multirow[t]{2}{*}{ NO2 (ppb) } & \multirow[t]{2}{*}{ O3 (ppb) } & \multicolumn{3}{|l|}{ PM2.5 $\left(\mu \mathrm{g} / \mathrm{m}^{3}\right)$} \\
\hline & & & & & MERV8 & MERV11 & MERV16 \\
\hline $1 \mathrm{~A}$ & Miami, FL & $\begin{array}{l}\text { Ambient } \\
\text { Mech_min } \\
\text { Nat_min } \\
\text { Mech_econ } \\
\text { Nat_econ }\end{array}$ & $\begin{array}{l}1.0(0.00,15) \\
0.31(0.00,4.0) \\
0.26(0.00,3.5) \\
0.35(0.00,5.9) \\
0.41(0.00,7.2)\end{array}$ & $\begin{array}{l}30(14,51) \\
3.6(1.7,6.2) \\
2.9(1.3,5.2) \\
3.9(1.8,18) \\
3.7(1.5,20)\end{array}$ & $\begin{array}{l}9.1(4.5,19) \\
4.1(2.2,8.4) \\
4.7(2.6,9.6) \\
4.4(2.2,9.8) \\
5.8(2.7,13)\end{array}$ & $\begin{array}{l}9.1(4.5,19) \\
1.4(0.64,3.6) \\
2.9(1.4,6.6) \\
1.5(0.65,4.5) \\
3.7(1.5,12)\end{array}$ & $\begin{array}{l}9.1(4.5,19) \\
0.33(0.14,1.3) \\
2.2(1.0,5.2) \\
0.34(0.14,1.2) \\
2.8(1.1,11)\end{array}$ \\
\hline $2 \mathrm{~A}$ & Houston, TX & $\begin{array}{l}\text { Ambient } \\
\text { Mech_min } \\
\text { Nat_min } \\
\text { Mech_econ } \\
\text { Nat_econ }\end{array}$ & $\begin{array}{l}8.8(2.7,32) \\
2.4(0.88,7.6) \\
2.1(0.74,7.6) \\
3.0(0.90,11) \\
3.3(0.79,13)\end{array}$ & $\begin{array}{l}22(0.95,53) \\
2.5(0.14,6.2) \\
2.3(0.13,5.8) \\
3.1(0.18,14) \\
3.1(0.20,16)\end{array}$ & $\begin{array}{l}9.4(3.7,21) \\
4.5(1.9,10) \\
5.3(2.2,12) \\
5.0(1.9,12) \\
6.4(2.4,15)\end{array}$ & $\begin{array}{l}9.4(3.7,21) \\
1.8(0.63,5.4) \\
3.6(1.2,10) \\
2.1(0.62,6) \\
4.8(1.4,13)\end{array}$ & $\begin{array}{l}9.4(3.7,21) \\
0.47(0.15,2.5) \\
2.8(0.89,8.8) \\
0.45(0.14,2.4) \\
4.0(1.1,12)\end{array}$ \\
\hline $2 B$ & Phoenix, AZ & $\begin{array}{l}\text { Ambient } \\
\text { Mech_min } \\
\text { Nat_min } \\
\text { Mech_econ } \\
\text { Nat_econ }\end{array}$ & $\begin{array}{l}16(4.0,46) \\
3.2(1.0,11) \\
2.9(0.89,11) \\
4.6(1.1,21) \\
4.0(0.94,20)\end{array}$ & $\begin{array}{l}26(1.0,60) \\
4.1(0.24,7.4) \\
3.6(0.27,7.1) \\
5.6(0.35,20) \\
5.0(0.35,18)\end{array}$ & $\begin{array}{l}9.5(3.0,20) \\
3.5(1.5,9.7) \\
4.4(1.9,12) \\
3.9(1.4,13) \\
5.4(1.9,17)\end{array}$ & $\begin{array}{l}9.5(3.0,20) \\
1.2(0.36,4.9) \\
2.8(0.78,11) \\
1.5(0.36,6.7) \\
3.7(0.97,16)\end{array}$ & $\begin{array}{l}9.5(3.0,20) \\
0.31(0.071,2.1) \\
2.1(0.48,9.3) \\
0.33(0.071,2.1) \\
3.0(0.59,15)\end{array}$ \\
\hline $3 A$ & Atlanta, GA & $\begin{array}{l}\text { Ambient } \\
\text { Mech_min } \\
\text { Nat_min } \\
\text { Mech_econ } \\
\text { Nat_econ }\end{array}$ & $\begin{array}{l}6.5(1.5,26) \\
1.6(0.39,6.0) \\
1.4(0.34,5.9) \\
2.0(0.50,8.2) \\
2.2(0.47,8.8)\end{array}$ & $\begin{array}{l}21(2.0,61) \\
3.3(0.24,7.5) \\
3.1(0.21,6.6) \\
4.1(0.25,19) \\
4.1(0.28,20)\end{array}$ & $\begin{array}{l}8.0(1.2,19) \\
3.7(0.92,9.2) \\
4.4(1.2,11) \\
4.2(0.96,11) \\
5.4(1.3,14)\end{array}$ & $\begin{array}{l}8.0(1.2,19) \\
1.5(0.34,5.2) \\
3.0(0.72,9.7) \\
1.8(0.38,5.8) \\
4.5(0.93,14)\end{array}$ & $\begin{array}{l}8.0(1.2,19) \\
0.39(0.079,2.5) \\
2.4(0.53,8.7) \\
0.42(0.084,2.4) \\
3.8(0.72,13)\end{array}$ \\
\hline 3B & El Paso, TX & $\begin{array}{l}\text { Ambient } \\
\text { Mech_min } \\
\text { Nat_min } \\
\text { Mech_econ } \\
\text { Nat_econ }\end{array}$ & $\begin{array}{l}10(3.1,35) \\
2.7(0.85,8.9) \\
2.4(0.75,8.8) \\
3.7(0.99,16) \\
3.2(0.86,14)\end{array}$ & $\begin{array}{l}32(1.2,58) \\
4.2(0.30,7.0) \\
3.7(0.32,6.4) \\
5.6(0.41,24) \\
4.7(0.40,21)\end{array}$ & $\begin{array}{l}6.4(1.9,18) \\
2.7(0.82,8.6) \\
3.3(1.1,11) \\
3.3(0.87,11) \\
4.1(1.2,13)\end{array}$ & $\begin{array}{l}6.4(1.9,18) \\
0.99(0.23,4.9) \\
2.1(0.57,9.9) \\
1.5(0.26,6.0) \\
3.2(0.69,12)\end{array}$ & $\begin{array}{l}6.4(1.9,18) \\
0.25(0.052,2.2) \\
1.5(0.41,8.9) \\
0.29(0.056,2.2) \\
2.7(0.50,12)\end{array}$ \\
\hline $3 C$ & $\begin{array}{l}\text { Los Angeles, } \\
\text { CA }\end{array}$ & $\begin{array}{l}\text { Ambient } \\
\text { Mech_min } \\
\text { Nat_min } \\
\text { Mech_econ } \\
\text { Nat_econ }\end{array}$ & $\begin{array}{l}12(2.7,40) \\
2.6(0.69,10) \\
2.4(0.62,10) \\
4.8(1.2,17) \\
5.0(1.3,18)\end{array}$ & $\begin{array}{l}27(0.62,52) \\
3.9(0.21,6.6) \\
3.5(0.20,6.1) \\
8.1(0.26,24) \\
9.0(0.29,24)\end{array}$ & $\begin{array}{l}12(0.010,37) \\
6.0(0.00,19) \\
6.9(0.010,22) \\
8.4(0.010,25) \\
11(0.010,33)\end{array}$ & $\begin{array}{l}12(0.010,37) \\
2.3(0.00,9.4) \\
4.4(0.00,18) \\
3.9(0.00,12) \\
10(0.010,31)\end{array}$ & $\begin{array}{l}12(0.010,37) \\
0.56(0.00,3.8) \\
3.3(0.00,15) \\
0.69(0.00,3.5) \\
9.4(0.010,30)\end{array}$ \\
\hline $4 \mathrm{~A}$ & $\begin{array}{l}\text { Philadelphia, } \\
\text { PA }\end{array}$ & $\begin{array}{l}\text { Ambient } \\
\text { Mech_min } \\
\text { Nat_min } \\
\text { Mech_econ } \\
\text { Nat_econ }\end{array}$ & $\begin{array}{l}14(5.0,36) \\
3.6(1.4,9.4) \\
3.2(1.3,8.6) \\
4.5(1.7,12) \\
4.4(1.6,12)\end{array}$ & $\begin{array}{l}18(1.2,40) \\
2.3(0.19,5.0) \\
2.0(0.16,4.8) \\
2.8(0.20,13) \\
2.6(0.19,13)\end{array}$ & $\begin{array}{l}15(6.8,31) \\
8.3(3.9,18) \\
9.9(4.7,21) \\
9.1(4.3,20) \\
12(5.6,26)\end{array}$ & $\begin{array}{l}15(6.8,31) \\
4.0(1.3,10) \\
7.6(2.9,19) \\
4.6(1.6,11) \\
10(3.9,24)\end{array}$ & $\begin{array}{l}15(6.8,31) \\
1.3(0.31,4.8) \\
6.3(2.1,17) \\
1.3(0.34,4.8) \\
9.0(2.9,23)\end{array}$ \\
\hline 4B & $\begin{array}{l}\text { Albuquerque, } \\
\text { NM }\end{array}$ & $\begin{array}{l}\text { Ambient } \\
\text { Mech_min } \\
\text { Nat_min } \\
\text { Mech_econ } \\
\text { Nat_econ }\end{array}$ & $\begin{array}{l}8.7(3.7,31) \\
2.3(1.1,8.2) \\
2.1(0.90,7.9) \\
3.8(1.3,11) \\
3.6(1.0,11)\end{array}$ & $\begin{array}{l}35(3.0,60) \\
4.6(0.49,7.2) \\
4.0(0.52,6.4) \\
6.4(0.60,26) \\
5.5(0.59,23)\end{array}$ & $\begin{array}{l}4.2(0.73,15) \\
2.0(0.47,7.0) \\
2.5(0.57,8.5) \\
2.5(0.51,8.2) \\
3.2(0.71,10)\end{array}$ & $\begin{array}{l}4.2(0.73,15) \\
0.84(0.14,3.8) \\
1.7(0.30,7.5) \\
1.2(0.19,4.5) \\
2.7(0.48,9.6)\end{array}$ & $\begin{array}{l}4.2(0.73,15) \\
0.23(0.031,1.8) \\
1.3(0.21,6.6) \\
0.27(0.036,1.8) \\
2.4(0.36,8.8)\end{array}$ \\
\hline $4 C$ & Seattle, WA & $\begin{array}{l}\text { Ambient } \\
\text { Mech_min } \\
\text { Nat_min } \\
\text { Mech_econ } \\
\text { Nat_econ }\end{array}$ & $\begin{array}{l}17(5.0,36) \\
4.5(1.4,9.8) \\
4.1(1.3,8.8) \\
5.6(1.7,16) \\
5.3(1.6,15)\end{array}$ & $\begin{array}{l}17(1.0,38) \\
2.1(0.12,4.8) \\
1.9(0.11,4.6) \\
2.8(0.12,12) \\
2.7(0.11,12)\end{array}$ & $\begin{array}{l}5.0(1.7,14) \\
2.8(1.1,7.6) \\
3.4(1.3,9.2) \\
3.3(1.2,8.2) \\
4.1(1.5,10)\end{array}$ & $\begin{array}{l}5.0(1.7,14) \\
1.4(0.47,4.5) \\
2.8(0.96,8.5) \\
1.7(0.62,4.6) \\
3.9(1.4,9.6)\end{array}$ & $\begin{array}{l}5.0(1.7,14) \\
0.48(0.13,2.1) \\
2.4(0.75,7.7) \\
0.50(0.15,2.1) \\
3.5(1.2,8.9)\end{array}$ \\
\hline $5 \mathrm{~A}$ & Boston, MA & $\begin{array}{l}\text { Ambient } \\
\text { Mech_min } \\
\text { Nat_min } \\
\text { Mech_econ } \\
\text { Nat_econ }\end{array}$ & $\begin{array}{l}16(6.0,35) \\
4.4(1.8,9.2) \\
3.7(1.6,8.0) \\
5.3(2.1,13) \\
4.9(1.9,13)\end{array}$ & $\begin{array}{l}22(3.0,42) \\
2.9(0.48,5.4) \\
2.5(0.41,5.0) \\
3.4(0.50,15) \\
3.1(0.46,14)\end{array}$ & $\begin{array}{l}8.5(2.6,23) \\
4.8(1.6,13) \\
5.6(1.8,15) \\
5.3(1.8,14) \\
6.5(2.3,17)\end{array}$ & $\begin{array}{l}8.5(2.6,23) \\
2.4(0.58,7.7) \\
4.7(1.1,14) \\
2.8(0.75,7.8) \\
5.9(1.8,15)\end{array}$ & $\begin{array}{l}8.5(2.6,23) \\
0.86(0.14,3.4) \\
3.9(0.84,12) \\
0.86(0.16,3.4) \\
5.2(1.4,14)\end{array}$ \\
\hline $5 B$ & $\begin{array}{l}\text { Salt Lake City, } \\
\text { UT }\end{array}$ & $\begin{array}{l}\text { Ambient } \\
\text { Mech_min } \\
\text { Nat_min } \\
\text { Mech_econ } \\
\text { Nat_econ }\end{array}$ & $\begin{array}{l}13(2.0,48) \\
3.2(0.66,13) \\
2.9(0.60,11) \\
4.4(0.88,14) \\
4.0(0.79,13)\end{array}$ & $\begin{array}{l}30(7.0,54) \\
4.2(1.0,6.6) \\
3.6(0.95,6.2) \\
5.2(1.1,20) \\
4.6(1.1,18)\end{array}$ & $\begin{array}{l}5.5(0.80,47) \\
2.6(0.8,31) \\
3.2(0.98,37) \\
3.3(0.83,31) \\
4.2(1.1,37)\end{array}$ & $\begin{array}{l}5.5(0.80,47) \\
1.1(0.23,18) \\
2.4(0.51,33) \\
1.6(0.27,18) \\
3.7(0.70,33)\end{array}$ & $\begin{array}{l}5.5(0.80,47) \\
0.34(0.052,7.2) \\
1.9(0.35,29) \\
0.38(0.056,7.2) \\
3.4(0.52,29)\end{array}$ \\
\hline $6 \mathrm{~A}$ & Milwaukee, WI & $\begin{array}{l}\text { Ambient } \\
\text { Mech_min } \\
\text { Nat_min } \\
\text { Mech_econ }\end{array}$ & $\begin{array}{l}7.7(1.6,26) \\
2.0(0.46,6.4) \\
1.8(0.42,5.7) \\
2.6(0.55,9.3)\end{array}$ & $\begin{array}{l}28(3.9,53) \\
3.6(0.82,6.5) \\
3.2(0.74,6.1) \\
4.4(0.95,20)\end{array}$ & $\begin{array}{l}9.0(3.0,23) \\
4.9(1.7,14) \\
5.8(2.1,16) \\
5.6(1.9,15)\end{array}$ & $\begin{array}{l}9.0(3.0,23) \\
2.3(0.64,7.8) \\
4.4(1.3,14) \\
2.9(0.76,8.2)\end{array}$ & $\begin{array}{l}9.0(3.0,23) \\
0.81(0.15,3.6) \\
3.6(0.96,13) \\
0.84(0.17,3.5)\end{array}$ \\
\hline
\end{tabular}




\begin{tabular}{|c|c|c|c|c|c|c|c|}
\hline & & Nat_econ & $2.3(0.51,9.5)$ & $4.1(0.88,18)$ & $6.6(2.2,18)$ & $5.6(1.5,17)$ & $4.9(1.2,16)$ \\
\hline $6 \mathrm{~B}$ & Billings, MT & $\begin{array}{l}\text { Ambient } \\
\text { Mech_min } \\
\text { Nat_min } \\
\text { Mech_econ } \\
\text { Nat_econ }\end{array}$ & $\begin{array}{l}2.0(0.00,13) \\
0.61(0.079,4.0) \\
0.57(0.12,3.6) \\
0.77(0.00,5.3) \\
0.72(0.00,5.0)\end{array}$ & $\begin{array}{l}30(7.0,54) \\
4.3(1.0,6.6) \\
3.7(0.93,6.3) \\
5.1(1.1,23) \\
4.5(1.0,19)\end{array}$ & $\begin{array}{l}4.0(0.00,17) \\
2.3(0.11,8.1) \\
2.8(0.14,9.8) \\
2.7(0.068,11) \\
3.4(0.10,13)\end{array}$ & $\begin{array}{l}4.0(0.00,17) \\
0.99(0.037,4.4) \\
2.0(0.070,8.4) \\
1.3(0.030,5.4) \\
2.8(0.065,12)\end{array}$ & $\begin{array}{l}4.0(0.00,17) \\
0.30(0.010,1.9) \\
1.6(0.036,7.6) \\
0.35(0.010,1.9) \\
2.3(0.037,11)\end{array}$ \\
\hline $7 \mathrm{~B}$ & Fargo, ND & $\begin{array}{l}\text { Ambient } \\
\text { Mech_min } \\
\text { Nat_min } \\
\text { Mech_econ } \\
\text { Nat_econ }\end{array}$ & $\begin{array}{l}2.8(0.00,16) \\
0.64(0.00,4.1) \\
0.56(0.00,3.3) \\
0.83(0.00,4.6) \\
0.72(0.00,3.9)\end{array}$ & $\begin{array}{l}28(7.0,49) \\
3.7(0.99,6.2) \\
3.0(0.86,5.8) \\
4.4(1.2,18) \\
3.8(1.0,16)\end{array}$ & $\begin{array}{l}3.4(0.00,12) \\
1.9(0.23,5.9) \\
2.1(0.28,6.8) \\
2.1(0.18,7.0) \\
2.5(0.24,9.1)\end{array}$ & $\begin{array}{l}3.4(0.00,12) \\
0.89(0.070,3.2) \\
1.6(0.15,5.8) \\
1.1(0.067,3.8) \\
2.1(0.16,8.6)\end{array}$ & $\begin{array}{l}3.4(0.00,12) \\
0.32(0.016,1.4) \\
1.3(0.09,5.1) \\
0.34(0.014,1.3) \\
1.7(0.11,8.0)\end{array}$ \\
\hline
\end{tabular}


Table 8. For minimum ventilation cases, I/O ratio distribution median (5th and 95th) percentiles for pollutants and $k$, which is the squared ratio of the 95th and 5th percentiles. For economizing cases, fits of $\mathrm{I} / \mathrm{O}$ ratios as a function of ventilation $A E R$, as well as $R^{2}$ and normalized root mean squared error (NRMSE) for the fits.

\begin{tabular}{|c|c|c|c|c|c|c|}
\hline \multirow[b]{2}{*}{ Pollutant } & & \multicolumn{5}{|l|}{ Mechanical Ventilation } \\
\hline & & I/O at Mech_min & $\boldsymbol{k}_{i}$ & I/O at Mech_econ & $R^{2}$ & RMSE \\
\hline $\mathrm{CO}_{2}$ & & $1.64(1.62,1.66)$ & 1.05 & $\mathrm{I} / \mathrm{O}=-0.248 \lambda_{v}+1.69$ & 0.76 & 0.071 \\
\hline $\mathrm{CO}$ & & $1.03(0.99,1.14)$ & 1.31 & $\mathrm{I} / \mathrm{O}=-0.0240 \lambda_{v}+1.05$ & 0.090 & 0.038 \\
\hline $\mathrm{NO}_{2}$ & & $0.270(0.270,0.290)$ & 1.15 & $\mathrm{I} / \mathrm{O}=0.179 \lambda_{v}+0.217$ & 0.97 & 0.015 \\
\hline $\mathrm{O}_{3}$ & & $0.121(0.116,0.127)$ & 1.19 & $\mathrm{I} / \mathrm{O}=0.138 \lambda_{v}+0.074$ & 0.98 & 0.009 \\
\hline \multirow[t]{2}{*}{$\mathrm{HCHO}$} & $k L=1.6 \mathrm{~h}^{-1}$ & $6.79(6.70,6.82)$ & 1.04 & $\mathrm{I} / \mathrm{O}=-1.37 \lambda_{v}+7.20$ & 0.99 & 0.079 \\
\hline & $k L=0.05 \mathrm{~h}^{-1}$ & $7.11(6.64,7.40)$ & 1.24 & $\mathrm{I} / \mathrm{O}=-2.22 \lambda_{v}+7.53$ & 0.95 & 0.268 \\
\hline \multirow[t]{3}{*}{$\mathrm{PM}_{2.5} T_{\mathrm{OA}}>T_{\text {bal }}$} & MERV8 & $0.445(0.371,0.548)$ & 2.18 & $\mathrm{I} / \mathrm{O}=0.141 \lambda_{v}+0.374$ & 0.72 & 0.044 \\
\hline & MERV11 & $0.166(0.121,0.221)$ & 3.32 & $\mathrm{I} / \mathrm{O}=0.101 \lambda_{v}+0.105$ & 0.73 & 0.030 \\
\hline & MERV16 & $0.0492(0.0319,0.0761)$ & 5.69 & $\mathrm{I} / \mathrm{O}=0.019 \lambda_{v}+0.030$ & 0.37 & 0.012 \\
\hline \multirow[t]{4}{*}{$\mathrm{PM}_{2.5} T_{\mathrm{OA}}<T_{\text {bal }}$} & MERV8 & $0.679(0.532,0.810)$ & 2.32 & $\mathrm{I} / \mathrm{O}=-0.009 \lambda_{v}+0.750$ & 0.00 & 0.102 \\
\hline & MERV11 & $0.370(0.227,0.438)$ & 3.74 & $\mathrm{I} / \mathrm{O}=-0.036 \lambda_{v}+0.439$ & 0.06 & 0.067 \\
\hline & MERV16 & $0.155(0.0859,0.189)$ & 4.83 & $\mathrm{I} / \mathrm{O}=-0.049 \lambda_{v}+0.194$ & 0.35 & 0.033 \\
\hline & & \multicolumn{5}{|l|}{ Natural Ventilation } \\
\hline Pollutant & & I/O Nat_min & $\boldsymbol{k}_{i}$ & I/O at Nat_econ & $R^{2}$ & RMSE \\
\hline $\mathrm{CO}_{2}$ & & $1.75(1.64,1.83)$ & 1.25 & $\mathrm{I} / \mathrm{O}=-0.337 \lambda_{v}+1.83$ & 0.73 & 0.101 \\
\hline $\mathrm{CO}$ & & $1.03(0.992,1.18)$ & 1.41 & $\mathrm{I} / \mathrm{O}=-0.034 \lambda_{v}+1.06$ & 0.13 & 0.043 \\
\hline $\mathrm{NO}_{2}$ & & $0.243(0.218,0.285)$ & 1.70 & $\mathrm{I} / \mathrm{O}=0.210 \lambda_{v}+0.176$ & 0.97 & 0.019 \\
\hline $\mathrm{O}_{3}$ & & $0.107(0.0926,0.128)$ & 1.90 & $\mathrm{I} / \mathrm{O}=0.151 \lambda_{v}+0.055$ & 0.98 & 0.009 \\
\hline \multirow[t]{2}{*}{$\mathrm{HCHO}$} & $k L=1.6 \mathrm{~h}^{-1}$ & $6.96(6.73,7.11)$ & 1.11 & $\mathrm{I} / \mathrm{O}=-1.51 \lambda_{v}+7.38$ & 0.97 & 0.135 \\
\hline & $k L=0.05 \mathrm{~h}^{-1}$ & $8.02(6.88,8.99)$ & 1.71 & $\mathrm{I} / \mathrm{O}=-3.02 \lambda_{v}+8.48$ & 0.92 & 0.457 \\
\hline \multirow[t]{3}{*}{$\mathrm{PM}_{2.5} T_{\mathrm{OA}}>T_{\text {bal }}$} & MERV8 & $0.521(0.453,0.675)$ & 2.23 & $\mathrm{I} / \mathrm{O}=0.201 \lambda_{v}+0.480$ & 0.75 & 0.054 \\
\hline & MERV11 & $0.311(0.241,0.415)$ & 2.96 & $\mathrm{I} / \mathrm{O}=0.300 \lambda_{v}+0.201$ & 0.90 & 0.048 \\
\hline & MERV16 & $0.228(0.173,0.325)$ & 3.53 & $\mathrm{I} / \mathrm{O}=0.317 \lambda_{v}+0.105$ & 0.91 & 0.046 \\
\hline \multirow[t]{3}{*}{$\mathrm{PM}_{2.5} T_{\mathrm{OA}}<T_{\text {bal }}$} & MERV8 & $0.811(0.643,1.02)$ & 2.50 & $\mathrm{I} / \mathrm{O}=0.029 \lambda_{v}+0.903$ & 0.01 & 0.169 \\
\hline & MERV11 & $0.716(0.447,0.903)$ & 4.07 & $\mathrm{I} / \mathrm{O}=0.056 \lambda_{v}+0.803$ & 0.23 & 0.158 \\
\hline & MERV16 & $0.620(0.363,0.788)$ & 4.72 & $\mathrm{I} / \mathrm{O}=0.095 \lambda_{v}+0.679$ & 0.11 & 0.130 \\
\hline
\end{tabular}

